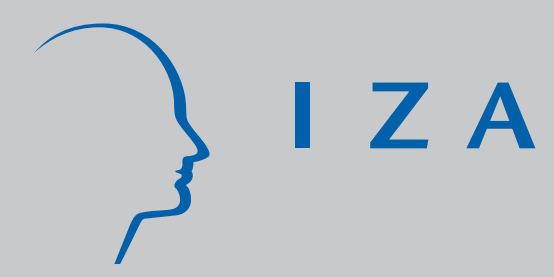

IZA DP No. 1448

Impact of Income Growth and Economic Reform on Nutrition Intake in Urban China: 1986-2000

Xin Meng

Xiaodong Gong

Youj uan Wang

December 2004 


\title{
Impact of Income Growth and Economic Reform on Nutrition Intake in Urban China: 1986-2000
}

\author{
Xin Meng \\ Australian National University \\ Xiaodong Gong \\ Australian National University and IZA Bonn \\ Youjuan Wang \\ Chinese State Statistical Bureau
}

Discussion Paper No. 1448

December 2004

\author{
IZA \\ P.O. Box 7240 \\ 53072 Bonn \\ Germany \\ Phone: +49-228-3894-0 \\ Fax: +49-228-3894-180 \\ Email: iza@iza.org
}

\begin{abstract}
Any opinions expressed here are those of the author(s) and not those of the institute. Research disseminated by IZA may include views on policy, but the institute itself takes no institutional policy positions.
\end{abstract}

The Institute for the Study of Labor (IZA) in Bonn is a local and virtual international research center and a place of communication between science, politics and business. IZA is an independent nonprofit company supported by Deutsche Post World Net. The center is associated with the University of Bonn and offers a stimulating research environment through its research networks, research support, and visitors and doctoral programs. IZA engages in (i) original and internationally competitive research in all fields of labor economics, (ii) development of policy concepts, and (iii) dissemination of research results and concepts to the interested public.

IZA Discussion Papers often represent preliminary work and are circulated to encourage discussion. Citation of such a paper should account for its provisional character. A revised version may be available directly from the author. 


\title{
ABSTRACT \\ Impact of Income Growth and Economic Reform on Nutrition Intake in Urban China: 1986-2000*
}

\begin{abstract}
Although urban China has experienced a rapid income growth over the last twenty years, nutrition intake for the low income group declined in the 1990s. Does this imply a zero or negative income elasticity for the low income group? This paper examines this issue using large representative sample of repeated cross-sectional data for the period 1986-2000. It is found that income elasticities of calorie consumption for urban households are far from zero, and the lower the income level the higher the income elasticity. The main reason for the reduction in calorie consumption for the low income group in the early 1990s was a sharp increase in food price. In addition, in the mid to late 1990s large scale social welfare reform increased households' need to pay for education, medical, housing expenses and the need to save for future consumption and income uncertainty. These factors seem to have played an important role in suppressing nutrition consumption of the low income group during this period.
\end{abstract}

JEL Classification: I31, D31, O40, O15

Keywords: poverty, income growth, inequality, China

Corresponding author:

Xin Meng

Department of Economics

Research School of Pacific and Asian Studies

Australian National University

Canberra 0200

Australia

Email: Xin.Meng@anu.edu.au

\footnotetext{
* Financial support from the Australian Research Council is acknowledged.
} 


\section{Introduction}

China has experienced a rapid income growth over the last twenty years, especially in urban areas. This, however, may not necessarily have led to an improvement in the economic wellbeing of the population at large. Many factors could have provented the growth effect from trickling down to low income groups. These include changes in inequality, food prices, and income uncertainty. Indeed, despite the fast economic growth a recent ADB report (2002) stated that poverty had become a problem in the 1990s that potentially threatens a substantial percentage of the urban population.

Undernutrition is one of the most important measure of poverty (Deaton, 1997). It is, therefore, important to investigate the change in nutrition intake and factors affecting this change in order to understand the change in urban poverty. This paper is the first attempt to use national representative samples to map out nutrition intake of the urban population over a 15 year period of fast economic growth, which was accompanied by considerable price and social welfare reforms. We find that despite the rapid increase in income, the average nutrient consumption of low income urban households declined in the 1990s. The question naturally arises as to why this happened. Was it due to a decline in real income or an increase in relative food prices? Did economic uncertainty affect nutrient intake?

Recent literature on the effect of income on nutrition intake is divided into two broad schools. Some studies suggest that the income elasticity of nutrition intake is close to zero, indicating that malnutrition among the poor is unlikely to disappear in the normal course of economic development (Behrman and Deolalikar, 1987). Others found that the income elasticity of nutrition intake is far from zero, suggesting an increase in income will reduce malnutrition in the developing world (Strauss and Thomas, 1989; Ravallion, 1990; Bhargava, 1991; Subramanian and Deaton, 1996). This paper contributes to the literature by suggesting that fast monetary income growth plus an average non-zero income elasticity of nutrition intake may not necessarily lead to a reduction in malnutrition. Other economic factors, such as a change in relative food price, an increase in need to spend on non-food neccesities, and an increase in precautionary savings, may also be important contributors to this relationship, especially for an economy in 
transition.

Most previous studies of the demand for nutrition use cross-sectional data. This may limit the possible implications which can be drawn from these studies as cross-sectional data cannot be used to investigate the dynamic aspect of income changes over time on nutrition intake. The advantage of the current study is the use of over 15 years of repeated cross-sectional data from 1986 to 2000, when household income increased markedly, enabling investigation of the dynamic aspect of the relationship between income and nutrition over a fast income growing period. The special feature of Chinese economic reform during this data period also makes it feasible to test the effect of price reform and change in income uncertainty on nutrition intake. Furthermore, it is commonly believed that the response of calorie intake to income changes is different between rich and poor. To allow for this heterogeneity and at the same time to control for other contributing factores, the relationship between income and calorie intake is estimated using a semiparametric model.

The paper is structured as follows. The next section provides background for the change in economic environment in China over the period 1986 to 2000. Section 3 discusses data and presents some summary statistics. Section 4 introduces analytical methodology and presents the results. Conclusions and policy implications are given in section 5

\section{Background}

In the past two decades urban households have experienced some unprecedented changes in the price system, income levels, and income uncertainty and all these changes affect nutrition intake.

Before economic reform began in 1978, due to the shortage of commodities, supply to the Chinese urban population was rationed and prices were set by the state. In particular, from the mid-1950s, all food products were sold in urban areas at highly subsidised prices operated through a coupon ration system, whereby coupons were distributed according to the number and age of family members. In the late 1970s and early 1980s, successful market oriented economic reform in the agriculture sector led to a significant increase in agriculture products. As a 
result, from the mid-1980s a two-tier food price system was introduced in urban areas, aimed at abolishing the coupon ration system. During that period, urban households still received subsidised coupon food products but were also free to purchase better and more variety of food at the market place. The two-tier price system lasted until the late 1980s and from 19911992, the government gradually increased subsidised food prices so that the two-tier prices were approaching each other (Tang, 1998). In 1993 most provinces (28 out of 31) abolished the coupon ration system (Crook, 1997; Tang, 1998; People's Daily, 2002). Over 1993 to 1996, food prices increased significantly and then stabilised. To compensate for abolition of the food coupon system, price subsidies were paid directly to urban workers' pay cheques. Non-working members of households, however, did not receive such subsidies. Thus, households with more non-working members received the least per capita compensation. From 1998, China experienced a prolonged period of deflation and consequently food prices reduced.

In addition to price changes, changes in income will also affect demand for nutrition. Although urban monetary income increased considerably over the reform period, the non-monetary component of income reduced in the 1990s due to various reform measures that were introduced. In the pre-reform era, urban households enjoyed a cradle to grave social welfare system, whereby individuals' health, education, housing, and old age pension were all fully covered or highly subsidised by the state. In the 1990s, these benefits began to be gradually removed, especially from the mid 1990s. Figure 1 presents the average household budget shares of medical, education, and housing expenditure over the period 1986 to 2000. It shows that household expenditure increased significantly on those components in the 1990s for both the average and poor households. Such a change may indicate a reduction in actual income. ${ }^{1}$ For example, assume individuals A and B have exactly the same level of income, but individual A has medical, education, and housing expenditure covered by the company while individual B has to pay these from his income. Obviously the actual income level of individual A is higher than that of individual B.

\footnotetext{
${ }^{1}$ Of course, this may also indicate that as income increases households are allocating more and more money into health, education, and housing which is unrelated to the abolition of the public cover. However, this effect may be very small. For example, in 1988 on average 66 per cent of the total medical bill were covered by the state, this figure in 1995 reduced to 49 per cent, and was further reduced to 20 per cent in 2002 according to Urban Household Income Distribution Surveys 1988, 1995, and 2002 conducted by the Institute of Economics at the Chinese Academy of Social Sciences. We believe that the trend of reduction in the state coverage in medical expenditure has contributed to the increase in household spending on medical care during the 1990s.
} 
Finally, an increase in income uncertainty may also contribute to a change in demand for nutrition. Radical enterprise reform in the state-owned enterprises (SOE) in the mid 1990s generated massive retrenchment. For the first time in their life SOE workers experienced job insecurity. According to the National Statistical Bureau data, around 6 to 10 million workers were retrenched between 1995 and 1997 (NSB, various years), while researchers find a much higher rate of unemployment (Meng, 2003; Giles, Park, and Cai, 2004). Thus, since the mid 1990s urban workers have been facing a real threat of being unemployed. On top of the job insecurity, abolition of the state provided health cover and old age pension also increased income uncertainties in the future. Furthermore, a gradual increase in school fees and liberalisation of the housing market implies more people began worrying about future expenditure. These uncertainties and expected future spending increase creates incentive to save (Carroll, 1994; and Carroll and Weil, 1994), and hence, a disincentive to consume.

Given all these changes, what happened to nutrition intake? The next section will map out Chinese urban household nutrition intake over 1986-2000, when most of these changes occurred.

\section{Data and the pattern of calorie consumption}

The data used in this study are from the Urban Household Income and Expenditure Surveys (UHIES) of 1986 to 2000, which were conducted annually by the National Statistical Bureau. The surveys cover around 13,000 to 17,000 households each year of urban permanent residents ${ }^{2}$ among all the provinces in China. Each household stays in the sample for three years and the sample frame has a 33 per cent rotation every year.

Information on income, quantity of goods purchased and total expenditure on each item are recorded daily by surveyed households throughout the year. In addition, the surveys also collect information on age, gender, education, occupation, industry of employment, ownership of employment of household members, region of resident, housing situation, and durable goods possession.

The questionnaire of the UHIES changed twice during the data period. The changes occurred

\footnotetext{
${ }^{2}$ Urban permanent residents are those who have urban household registration. Rural migrants are not included in the surveys.
} 
in 1988 and 1992, with the introduction of more detailed food categories in 1992 being the most relevant change for this study. Before 1992, 39 food items were included in the expenditure questions. Since 1992 the number was increased to 112. Consequently, some discontinuity in the data series can be expected.

The nutrient intakes are computed by using the quantity of food purchased and the nutrition content table provided by the Institute of Nutrition and Food Hygiene of China. The nutrition content table includes information on calories, fat, and protein, as well as on the proportion of food that can be consumed for a certain quantity of a food item. A small number of food categories (7 in the 1986-191 data and 9 in the 1992-2000 data), which are normally categorised as mischievous items in some large categories, do not have quantity data. ${ }^{3}$ This group accounts for 11 to 13 per cent of total food consumption over the period. For these items the average food price for the relevant category is used to calculate the 'quantity' of mischievous items and then the average nutrition content of that category is used to calculate nutrition intake. In addition to the food categories, there is also an item for eating out, which accounts for 5 to 15 per cent of total food consumption over the period. To calculate nutrition intake from restaurant food, it is assumed that half the expenditure in restaurants is for services. We, therefore, use the total value for eating out divided by an average food 'price' for each household times two to obtain the quantity of food consumed in restaurants and then use the average nutrition contents of all food items to calculate the nutrition intake from eating out. The total nutrition consumption for each household is then divided by 365 to obtain the daily nutrition intake of the households.

Following the convention (Subramanian and Deaton, 1996), the total expenditure data is taken net of purchases of durable goods. Both income and expenditure data are deflated using the urban consumer price index for each province at 1986 constant prices (National Statistical Bureau of China, various years). Using the quantities of each food item purchased and the amount of money spent, a variable for average food price at city level is also constructed.

An equivalent scale is used to adjust the household composition to get per capita measures of nutrition intake and income/expenditure. In doing so, household members aged zero to two are defined as infants, 3 to 14 as children, 15 to 65 as adult, and 66 and above as elderly. The

\footnotetext{
${ }^{3}$ These categories include unclasified tofu, seafood, dairy products, meat, drink, sugar or desert, and others.
} 
weight given to these categories are $0.35,0.5,1$, and 0.5 , respectively. ${ }^{4}$ Admittedly, it is difficult to justify the use of these weights, hence, a sensitivity test is given in the empirical section. Households with per capital daily calorie consumption below 500 or above 8000 are treated as outliers, and hence, excluded. This restriction excludes approximately 0.6 per cent to 1.5 per cent of the sample depending on the survey year.

Figure 2 presents the average daily per capita calorie, protein, and fat intakes (equivalent scale adjusted). It indicates that over the period 1986 to 1992 calorie intake did not change much. In 1993, however, it dropped significantly, recovering at a lower than 1992 level in 1994 but continuing to drop after that. This falling trend lasted until 1997 and although it recovered gradually from 1998 it never reached the level of 1992 and earlier. The changes in calorie intake depicted in this figure should not be a reflection of the discontinuity of the data due to the change in the survey questionnaire, as the questionnaire was changed in 1992, while the major drop in nutrient intake occurred from $1993 .{ }^{5}$

Is this decline in calorie intake a substitution effect, that is people consuming more protein and fat and hence, less calories? Figure 2 shows this is certainly not the case as protein and fat consumption also reduced sharply in 1993, along with a decline in calorie intake and the later recovery in calories, protein, and fat did not reach their pre-1992 levels until 1998.

This sharp decline in calorie intake is an unusual finding as calorie intake should normally increase with increasing income, although the increase may flatten out at some level of calorie intake (references). The sharp decline in calorie intake observed in this study is accompanied by a period of a significant increase in income level. Figure 3 depicts average real household income, total expenditure and food expenditure over the period. Real income of the top and the bottom 20 percentiles are also presented. The figure shows that both real household income and expenditure had increased significantly since the early 1990s, although real income of the bottom 20 percentiles increased far much less than that for the top 20 percentiles. The increase

\footnotetext{
${ }^{4}$ All the variables which are in per capita terms are equivalent scale adjusted, unless otherwise stated.

${ }^{5}$ The quantities of food items purchased for the sample households have the same trend over this period. The data on this are available upon request from the authors. The decline in calorie intake during this period is supported by another data set, the China Health and Nutrition Survey (CHNS), 1989, 1991, and 1993 by North Carolina University. The CHNS recorded three day food intakes for each individual and the calorie intake data revealed by that survey indicates that the adult (aged 20 to 45) daily calorie intake declined from 2923 in 1989 to 2734 in 1991 and 2615 in 1993.
} 
in household food expenditure has been very modest. The lack of increase in food expenditure, however, may not explain the decline in the nutrient intake in 1993 and thereafter, unless relative food prices have increased significantly.

Figure 4 presents the change in the food price relative to urban CPI. It shows that the relative food price increased very fast over 1992 to 1995 and the increase was the most significant in 1993 and 1995, which coincide with the significant drop in nutrient consumption in these two years. However, the drop in nutrient consumption between 1995 and 1997 cannot be explained by the decrease in relative food price. Note that this is the period where a massive retrenchment and significant reform in welfare provision occurred. Thus, the reduction in food price may be offset by the effective reduction in income and increase in income uncertainty during this period.

Further investigation reveals that the decline in nutrient intake during the mid 1990s occurred mainly in the low and middle income groups even though the 1993 and 1995 price changes affected almost all income groups (see Figure 5). For households at the bottom income decile the calorie intake has been declining since 1995 while households at other income deciles have had increases in calorie intake since 1998.

The decline in calorie intake of the low-income group may also be seen in Figure 6, where calorie consumption is shown by different food categories for the top and bottom 20 percentiles of income groups. It shows that although calories obtained from cereal declined over time for both rich and poor and calories from meat, eggs, and fish did not change much for either group, the decline in calories from cereal products was compensated by the sharp increase in calories obtained from eating out and fruit and vegetables for the rich. For the poor, however, calories from either eating out or fruit and vegetables hardly changed and, if anything, declined slightly during the 1993-1995 period. Figure 6 also shows that the calories obtained from meat-egg-fish for the rich is almost doubled that for the poor and the gap remains roughly constant over time.

The data presented above seems to indicate that the relationship between income growth and nutrition intake was zero or even negative for low and middle income groups in the 1990s. However, when the effects of food price reform and changes in the state provision of social welfare is taken into account the conclusion may be different. The food price change may explain a large part of the changes in nutrition intake during 1993 to 1995, but not the change since 
1995. The most important change since 1995 is the substantial increase in the need to save for future expenditure and the increase in economic uncertainty in urban China as discussed in the last section. While an increase in price may be offset by an increase in income, offsetting an increase in long-term economic uncertainty requires a substantial increase in income, which has never happened in low income urban households. Although an income increase has occurred in all income deciles, the need to spend on other things, such as children's education, health care, and housing, has also increased substantially. The summary statistics presented in this section indicate that what is normally perceived as the most important factors affecting nutrition consumption — income (measured by monetary income) change and income elasticity — may be less important in reducing malnutrition in a transitional economy where changes in nonmoneytary income occurs so often.

\section{Estimating the relationship between calorie intake and in- come}

\subsection{Methodology}

To investigate the impact of increases in moneytary income, food prices, reduction in nonmonetary income, and increases in future income uncertainty on nutrition intake, a calorie demand function is specified as follows:

$$
\log K_{i}=f\left(Y_{i}\right)+\gamma \log \left(P_{i}\right)+\delta U C_{i}+\beta X_{i}+\epsilon_{i}
$$

where $K$ is per capita calorie demand, $Y$ is per capita income/expenditure, $P$ is average per unit calorie price for the city where a household resides, $U C$ is a vector of variables indicating economic uncertainty, and $X$ is a vector of variables which affect calorie demand, including household compositions, demographic characteristics, and regional indicators. To take account of the possible nonlinear relationship between calorie intakes and price, interaction terms are used between price and dummy variable indicating income deciles to which each family belongs. In addition, as price levels differ significantly across cities due to regional income differential, 
city level average income is also controed for to wash out this effect. Following the literature with regard to the household compositions (for example, Deaton 1997), a group of variables indicating the proportions of children, female and male teenagers, adults, and elderly are included. Household demographic variables include the proportion of female members in a household and the age (in linear and quadratic terms) and education level of the household head. To control for the activity level, a group of dummy variables indicating the occupation of the household head and a variable indicating the proportion of household members not working are also included. Unfortunately the data used in this study do not include measures of the weight and height of household members, and this might cause our estimation to suffer from the omitted variable problem. In particular, as income tends to be positively correlated to body mass index, the estimated income elasticity of calorie intake may be over-estimated.

To understand the effect of change in the non-monetary component of income and economic uncertainty on calorie consumption, two variables are used as proxies: the proportion of household labour force working in the state sector and the savings rate for each household. The reason the proportion of labour force working in the state sector is an indicator for change in non-monetary income and economic uncertainty is because many social benefits provided prior to the 1990s reform, such as public housing, health care, and old age pension, were mainly available to state sector employees. The reform, therefore, is expected to affect state sector employees more than their private sector counterparts. In addition, the increase in state sector retrenchment also affected SOE employees more than others.

The savings rate is used to capture two things. It captures the effect of perceived future expenditure and future income uncertainty on calorie consumption. In general, given the income level, the higher the savings, the lower the consumption. However, the dependent variable used is not general consumption, but calorie intake. The effect of savings rate, thus, may also capture the effect of saving on food vs. non-food consumption. Given that the need to spend on non-food necessities, such as eduction, health care, and housing increased significantly over the 1990s, it would be expected that the negative effect of savings on calorie consumption could increase in the 1990s.

If $f\left(Y_{i}\right)$ is specified, for example as log expenditure itself, equation (1) is a normal paramet- 
ric model. A parametric specification for the relationship between calorie intake and income, like the traditional Pig-log models, may suffer from incorrect specification of the nonlinear relationship between calorie intake and income, and hence, generate inconsistent estimates. The possible non-linearity may be due, for example, to the fact that some goods contain many calories and are cheap while others contain fewer calories but are more expensive (Subramanian and Deaton, 1996). If $f\left(Y_{i}\right)$ is not specified, i.e., is assumed to be an unknown function, equation (1) becomes a partial linear model, where the flexibility of the relationship between expenditure and calorie intake is allowed and, at the same time, the relationship with other variables is assumed to be linear. It would be ideal to specify the whole relationship in equation (1) non-parametrically. This, however, will suffer from the "curse of dimensionality", where too many cells will make it infeasible to estimate with a finite sample.

The partial linear model is estimated using the approach proposed by Yatchew (1997). The basic idea introduced in Yatchew (1997) is a two-step procedure. The sample is first ranked according to $Y$, and the first difference of equation (1) is taken to obtain:

$$
\Delta \log K_{i}=\Delta f\left(Y_{i}\right)+\gamma \Delta \log P_{i}+\delta \Delta U C_{i}+\beta \Delta X_{i}+\Delta \epsilon
$$

where $\Delta$ of a variable stands for the difference between observation $i$ and $i-1$. Given that $Y_{i}$ is bounded as the sample size increases, $\Delta f\left(Y_{i}\right) \approx 0$ as $f\left(Y_{i-1}\right)$ tends to cancel $f\left(Y_{i}\right)$. Providing $Y$ and other independent variables are not perfectly correlated, the OLS estimation of equation (2) will give consistent estimates of $\beta, \delta$, and $\gamma$. The second step is to use $\hat{\beta}, \hat{\delta}$ and $\hat{\gamma}$ obtained from the estimation of equation (2) to get:

$$
u_{i}=\log K_{i}-\hat{\gamma} \log \left(P_{i}\right)+\hat{\delta} U C_{i}+\hat{\beta} X_{i}=f\left(Y_{i} \hat{)}+\epsilon_{i}\right.
$$

and then apply non-parametric methods to estimate the relationship between $\log K_{i}$ and $f(Y)$. Due to possible biases associated with kernel regressions especially at end points (see, for example, the discussion by, Fan, 1992 and Deaton, 1997), a local weighted regression method is used. Equation (1) is also estimated parametrically as a comparison. 


\subsection{Estimation results}

In the empirical literature, the calorie/income relationship is often estimated using an expenditure measure to proxy income. This is either due to a lack of income data or a belief that income data are more likely to suffer from a measurement error problem. In our data household income variable is available. More importantly, in a period where significant institutional changes induced household saving behaviour changes, it would be expected that the change in the effect of income on calorie intake might be very different from the changes in the effect of expenditure on calorie intake. In addition, the effect of saving on calorie intake will only make sense in an equation where income rather than expenditure is used. Therefore, both the change in income elasticity and expenditure elasticity will be examined. ${ }^{6}$ To make our results comparable with the literature, we mainly report the results using expenditure measure, unless otherwise stated.

Equation (1) is estimated separately ${ }^{7}$ for each year using the Yatchew (1997) method (equation ??) and the full results are presented in Tables B1 and B2 of Appendix B. ${ }^{8}$ We first examine the expenditure/income elasticities, which are presented in Table 1 and Figures 7 and 8. Several important phonomena are observed.

First, over time the expenditure/income elasticity reduced significantly. For example, in 1987 the income and expenditure elasticities at the 50th percentile are 0.58 and 0.69 and in 2000 had reduced to 0.32 and 0.40 , respectively. ${ }^{9}$ These elasticities are far greater than zero, suggesting that increase income or expenditure has significant impact on reduction of malnutrition.

Second, the reduction in income/expenditure elasticities is much faster for the rich than for the poor. The higher the household income/budget, the less responsive is the calorie consumption. The relationship in early years, however, are much flatter than in the later years. For

\footnotetext{
${ }^{6}$ Expenditure elasticity is used to indicate income elasticity where income is proxied by expenditure.

${ }^{7} \mathrm{~A}$ test for the null hypotheses that the coefficients are the same over each adjacent year is conducted and the null hypothesis is rejected for all pairs. The test results are reported in Appendix A.

${ }^{8}$ Equation ?? is also estimated using OLS and the results on the parametric variables are consistent with those estimated in the partial linear model as presented in Appendix B. The full results of the OLS estimation are available upon requestion from the authors.

${ }^{9}$ Not controlling for savings, the income and expenditure elasticities are 0.45 and 0.53 in 1989 and reduce to 0.22 and 0.38 in 2000 respectively. The full results without controlling for saving rate are available upon request from the authors.
} 
example, in 1986, there was no significant difference in the expenditure elasticities between the rich and the poor (the point estimtes for the top decile and the bottom decile income groups are both 0.76 ). However, by 2000, the elasticity for the two income groups had changed to 0.34 and 0.54 , respectivly. There are two possible reasons for the lack of change in expenditure elasticities for the poor. One is that the initial level of calorie consumption for the poor was much lower than that for the rich, and hence, it will take longer for the poor to reach a high level calorie consumption. Another possibility is that the expenditure increase for the poor is much slower than for the rich. Table 2 presents the level of expenditure for different income groups over time. It indicates that over the 15 year period, the expenditure level for the 10th percentile only increased 12 per cent while that for the 90 th percentile increased by 80 per cent. The difference in the curvatures of the curves presented in Figures 7 and 8 between the 1980s and 1990s may reflect the increase in income dispersion. These variations also show that the linear model is too restrictive by assuming elasticity being the same across all income/expenditure groups. Moreover, with higher income/expenditure elasticity for the poor than for the rich, it is clear that an increase in income/expenditure certainly plays a significant role in reducing malnutrition.

Third, for households at the lowest income/expenditure decile, the trend of elasticity decline was significantly reversed in 1993. Skoufias (2003) finds that income elasticity of calorie intake is higher when price increases significantly and the effect is most obvious for the low income group. Our results seems to confirm his finding. ${ }^{10}$

Fourth, income elasticities depicted in Figure 8 appear to be more volatile than the expenditure elasticities, especially in the early years (1986 to 1992). In addition, it seems that in the early period income elasticity increases as income increases and this trend is true for most income groups. The elasticity then starts to drop sharply at high income level. This pattern is observed in Figure 7 as well but the turning point for expenditure elasticity is at a much lower expenditure level. This pattern is not usual and the reason is not entirely clear to us.

Finally, the most interesting finding from comparison of expenditure and income elasticities

\footnotetext{
${ }^{10}$ Although Skoufias (2003) finds a change in income elasticity between 1999 when price is high and 1996 when price level is normal and the difference is statistically significant, he concludes that the change is very small.
} 
(top and bottom panel of Table 1 and Figures 7 and 8) is that the income elasticities are lower than expenditure elasticities, suggesting that savings behaviour plays an important role with regard to calorie consumption. This is especially true in the 1990s, when future expected income reduced and income uncertainty increased. For example, comparing the bottom left corner of Figures 7 and 8 (for the year 1994-1997), much flatter curvatures are observed for income elasticities than for expenditure elasticities. The point estimates presented in Table 1 also confirm this.

The results obtained in this study indicate a similar variation of expenditure elasticities across different expenditure distribution as presented in Subramanian and Deaton (1996) using data from rural India and in Skoufias (2003) using data for Indonesia. Subramanian and Deaton (1996) find that expenditure elasticities range from 0.3 to 0.5, while Skoufias (2003) presented a range from 0.1 to 0.4 . The methodology used in their studies, however, is a non-parametric estimation, which is not comparable to the partial linear model used in this study.

To our knowledge, only one previous study investigated income elasticity of calorie consumption in China (Guo, Mroz, Popkin, and Zhai, 2000) using CHNS 1989-1993. Their estimations, however, are negative for 1989 and increased slightly by 1993. As the estimation method and results are not presented fully in their paper, it is very hard to understand why this would be the case. We suspect it may relate to the fact that they grouped rural and urban samples, but even that is not clearly stated in their paper. Nevertheless, as indicated in Subramanian (2003) it is common to observe low income elasticities using data from surveys designed to monitor nutrition.

Turning to the other determinants of calorie intake, it is found that the price elasticities are negative and significant for all income categories over all years. The general pattern is that the the higher the income the smaller the price elasticities. In addition, the price elasticity is larger in the 1990s than in the 1980s for almost all income groups and the difference between income groups becomes larger in the later years. This implies that poor households are more sensitive to price changes and this is more so in the 1990s than in the 1980s. Over the years, the price elasticity is the largest in 1992 and 1993, coinciding with the period of inflation and food price reform. In particular, for the low income groups (bottom two deciles) a 10 per cent 
increase in price leads to a 10 per cent reduction in calorie intake in these years. This is a very high price elasticity. Table 3 presents the effects of food price change on calorie consumption for three different income deciles: the first, second, and tenth. It shows that the annual price change in 1993 was 28 per cent and this change translated into a 30 per cent calorie reduction of the 1st income decile and a 24 per cent reduction for the 10 th income decile, ceteris paribus. For other years in the 1990s (excepting 1998), the price elasticities are between 0.7 and 0.8 for the low income groups, which are higher than in the 1980s. The pattern of the change in price elasticity closely follows the change in relative food price illustrated in Figure 4. The pattern of the price elasticity estimated in the equations with income measure is similar but at a lower level than the regression using expenditure measure.

Family characteristics play a significant role in calorie consumption. First, the fact that the coefficients of family size are all negatively significant means that the larger the family the less calories consumed per capita in the family, implying economy of scale. Males consume more calories than females, suggested by the positive and significant coefficients for the sex-ratio variable. The effect of household composition presents some unusual patterns. For example, relative to adult males, adult females, young children, and the elderly consumed more calories for most of the survey years, while teenagers consumed less. This may be related to the equivalent scale adjustment of the calorie intake. Indeed, when using unadjusted calorie intake as a dependent variable, most of the household composition variables switched signs and became negative and significant. ${ }^{11}$

The characteristics of household head are also important determinants. An inverse U-shaped relationship is observed between per capita calorie consumption and the age of household head, while households with a more educated head consume less calories. The education effect may capture part of the effect of physical activity levels of the household. In addition, occupation dummies are also used to capture physical activity levels and they indicate that a household head with a job that requires a higher level of physical activity consumes more calories.

Our main interest on the impact of expected and current reduction in non-monetary income, expected increase in future expenditure, and increase in income uncertainty is captured

\footnotetext{
${ }^{11}$ The results using unadjusted calorie intake as dependent variable are available upon request from the authors.
} 
by the proportion of state sector employees (irstate) and the household saving rate (rsave). With regard to the proportion of state sector employment, negative and significant effects are consistently observed for both estimations using income and expenditure measures. The effect increased in the 1990s when the radical reforms aimed at reducing state sector inefficiency and government provided welfare measures to the employees of the state sector were strongly enforced (see the discussions in Section 2).

The coefficient on savings rate has a negative and significant effect on calorie consumption in the equation where income is controlled for. This suggests that the more households save, the less they consume calories. The effect of saving on calorie consumption increased significantly in the 1990s. This may be related to the change of household expenditure structure over time. As discussed earlier, in the 1990s the need to spend on non-food necessaties, such as education, health care, and housing increased considerably due to the radical reform (see Figure 1). Thus, controlling for income, households are more likely to make savings from food rather than nonfood consumption.

\subsection{Sensitivity tests}

Are our results sensitive to the equivalence scale adjustment used? This subsection provides some sensitivity tests.

What constitutes a proper equivalence scale is an intensively debated topic in the literature (McClements, 1977; Coulter, Cowell, and Jenkins, 1992; Banks and Johnson, 1994). It is not easy to reach agreement on this. It is, therefore, better to test empirically how sensitive the results are to different equivalence scales.

The equivalence scale used in this paper assumes that infant (age 0 to 2) is equivalent to 0.35 of an adult, children (age 3-14) and the elderly (age above 65) are equal to 0.5 of an adult (adjustment 1). Rresults presented below use unadjusted calorie intake and expenditure/income measures, and a different equivalence scale adjusted measures, which count infant as 0.5 of an adult, and children and the elderly as 0.75 of an adult (adjustment 2).

Figure 9 presents the mean expenditure and calorie intake using three different adjustments. It shows that the adjustments increase the mean value of the variables but do not change the 
shape and the trend. We then estimated equation (2) using both unadjusted expenditure and calorie intake and adjustment 2. Table 4 presents the comparisons of expenditure elasticities at the 50th percentile from the estimation with expenditure measure and the coefficients on saving rate from the estimation with income measure for the three different equivalence scale adjustments, while Figures 10 and ?? depict the sensitivity of the adjustment on the semiparametric relationship between expenditure elasticities of calorie consumption. The results show that the trend on both expenditure elasticities and the effect of saving rate on calorie consumption are not sensitive to the equivalent scale adjustment used. The general pattern is that the less the infants, children, and the elderly are counted for as adult equivalents, the higher the estimated expenditure elasticities, and the less the negative saving effect. The differences in magnitudes are not large.

\section{Conclusions}

Although monetary income in urban China has increased significantly during the last two decades, the radical economic reform measures implemented in the 1990s acted as a counter weight by reducing and eventually abolishing many forms of government price subsidies and welfare provisions, reducing expected future monetary income and increasing income uncertainty.

This paper investigated the effect of a monetary income increase and the counter effects of the radical reform in the 1990s on households' nutritional consumption. We found that despite the monetary income increase, on average urban low income households reduced calorie consumption in 1993 due to abolition of the food coupon system, which heavily subsidised food products for urban households. Over the period where food prices increased dramatically, price elasticities also increased, especially for the low income group. In 1993, price elasticity for the bottom two income decile groups was above 1. Before households recovered from the price shock, the large scale social welfare reform increased their need to pay for education, medical, and housing expenses, and the need to save for future consumption and income uncertainty. This effect seems to have played an important role in suppressing the recovery of nutrition consumption to the pre-1993 level. We found that not only having more state sector employees 
reduced calorie consumption much more in the 1990s than in the 1980s, but the relationship between saving rate and calorie consumption also had a much larger negative effect on calorie consumption in the 1990s. The latter result may indicate that in the 1990s households saved at the expense of calorie consumption.

The analysis reveals a non-linear relationship between calorie intake and expenditure/income level. We observed that while in the 1980s the relationship was quite flat across different income levels, in the 1990s there existed much larger variations. This may be due to an increase in income dispersion in the 1990s. More interestingly we found that the expenditure elasticities were much higher than the income elasticities, and even more so for the low income group than for the high income group, suggesting that savings rate played a much bigger role in calorie consumption for the poor than it did for the rich. 


\section{References}

[1] Asian Development Bank, 2002, Research on Poverty in Urban China, Unpublished Report.

[2] Behrman, J. R. and Deolalikar, A. B., 1987, "Will developing country nutrition improve with income? A case study of rural south India", Journal of Political Economy, 95, pp. 108-138.

[3] Bhargava, A., 1991, "Estimating short and long run income elasticity of foods and nutrients for rural south India", Journal of the Royal Statistical Society, A, 154, pp. 157-174.

[4] Carroll, C. D., 1994, "How does future income affect current consumption?", Quarterly Journal of Economics, 109 (1), 111-147.

[5] Carroll, C. D. and D. N. Weil, 1994, "Saving and growth: a reinterpretation", Carnegie Rochester Conference Series on Public Policy, 40(0), 133-92.

[6] Coulter, F., Cowell, F.A., and Jenkins, S.P., 1992, "Equivalence scale relativities and the extent of inequality and poverty", Economic Journal, 102(414), pp. 1067-82.

[7] Crook, F., 1997, "China: is current Ag policy a retreat from reform?" Agricultural Outlook, Economic Research Service, USDA, March, 1997.

[8] Banks, J. and Johnson, P., 1994, "Equivalence scales and public policy", Fiscal Studies, 15(1), pp. 1-23.

[9] Deaton, A., 1997, The Analysis of Household Surveys-A Microeconometric Approach to Development Policy, Baltimore and London: Johns Hopkins University Press.

[10] Fan, J., 1992, "Design-adaptive non[arametric regression", Jounal of the American Statistical Association, 87, pp.998-1004.

[11] Giles, J., Park, A., and Cai, F., 2003, "How has economic restructuring affected China's urban workers?", unpublished manuscript.

[12] Guo, X., Mroz, T. A., Popkin, B. M., and Zhai, F., 2000, "Structural change in the impact of income on food consumption in China, 1989-1993", Economic Development and Cultural Change, 
[13] McClements, L. D., 1977, "Equivalence scales for children", Journal of Public Economics, 8(2), pp. 191-210.

[14] Meng, X., 2003, "Unemployment, consumption smoothing, and precautionary saving in urban China", Journal of Comparative Economics, 31(3), pp.465-485.

[15] National Statistical Bureau, various years, China Statistical Yearbook, Beijing: Chinese Statistical Press.

[16] People's Daily, 2002, "China finding earliest grain ration coupon", People's Daily, 4th July, 2002 .

[17] Ravallion, M., 1990, "Economic effects on undernutrition", Economic Developent and Cultural Change, 38(3), pp.489-515.

[18] Strauss, J. and Thomas, D., 1990, "The shape of the calorie expenditure curve", Economic Growth Centre Discussion Paper, No. 595, Yale University.

[19] Skoufias, E., 2003, "Is the calorie-income elasticity sensitive to price changes? Evidence from Indonesia", World Development, 31(7), pp.1291-1307.

[20] Subramanian, A., 2003, "Are income-calorie elasticity really high in developing countries? Some implications for nutrition and income", Unpublished manuscript.

[21] Subramanian, S. and A. Deaton, 1996, "The demand for food and calories", Journal of Political Economy, 104 (1), 133-162.

[22] Tang, Y., 1998, Choices: the Chinese Reform since 1978, Beijing: Economics Daily Publishing House.

[23] Yatchew, A. 1997, "An elementary estimator of the partial linear model", Economics Letters, 57, 135-143.

[24] Yatchew, A., 1998, "Nonparametric regression techniques in economics", Journal of Economic Literature, 36(2), 669-721. 
Figure 1: Budget share of health care, education and housing expenditure: 1986-2000

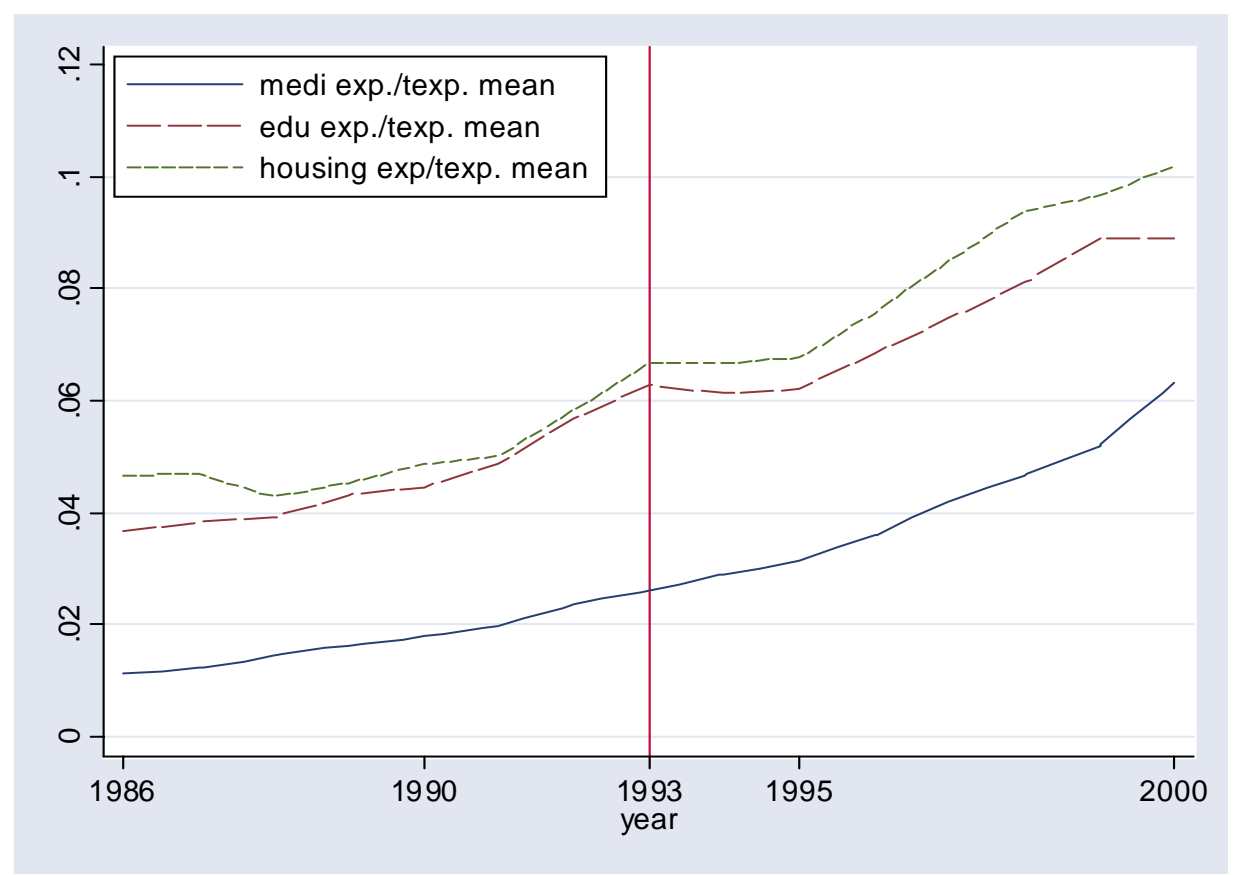

Figure 2: Change in nutrition intake: 1986-2000

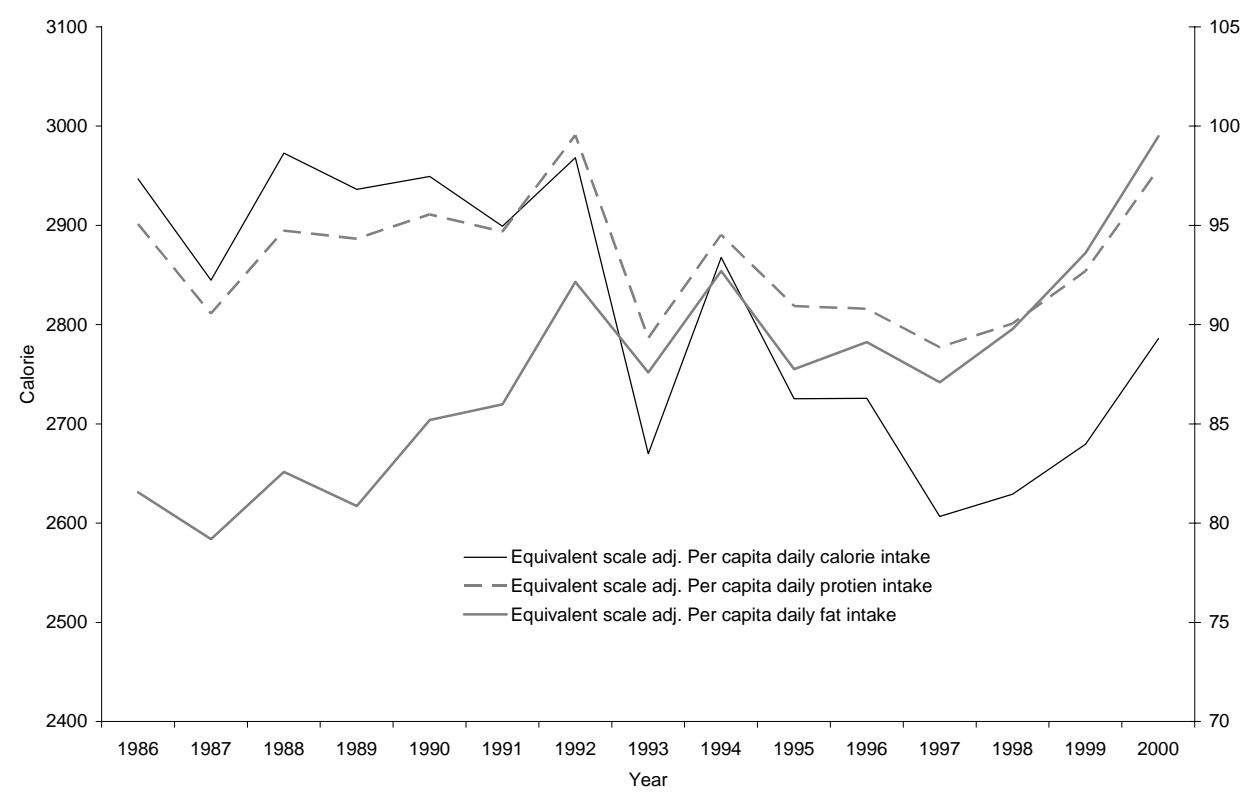


Figure 3: Relative food price and its annual change: 1986-2000

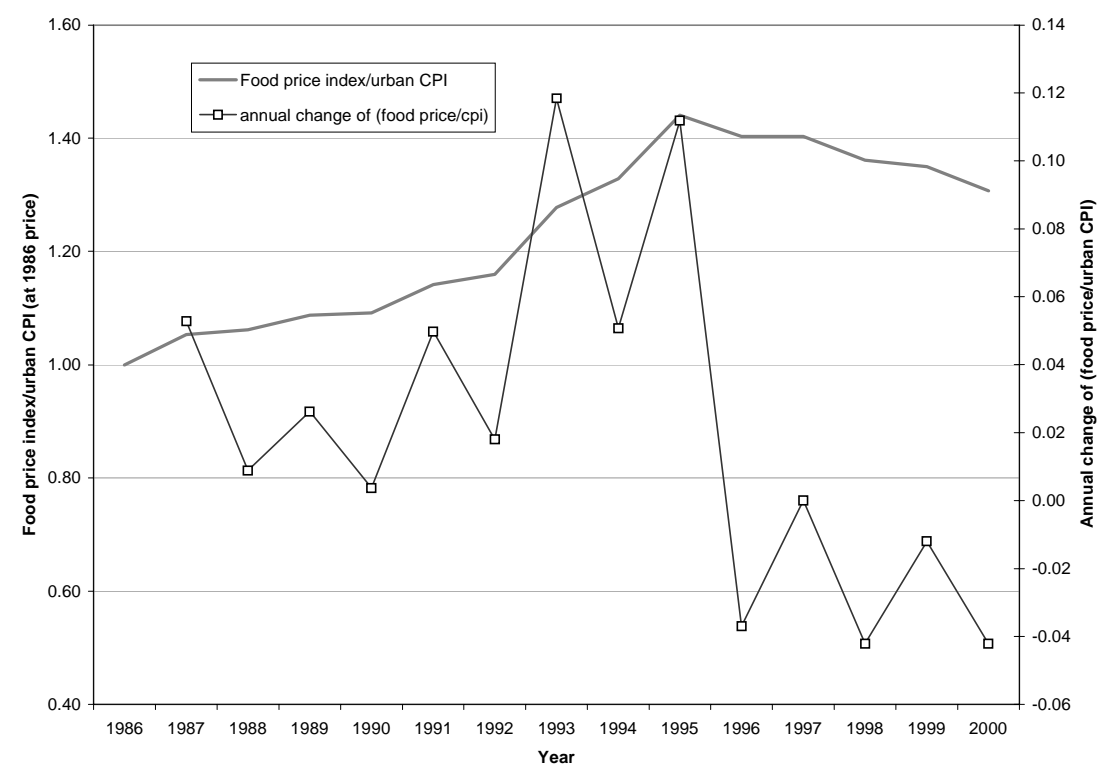

Figure 4: Calorie intake by income decile:1986-2000

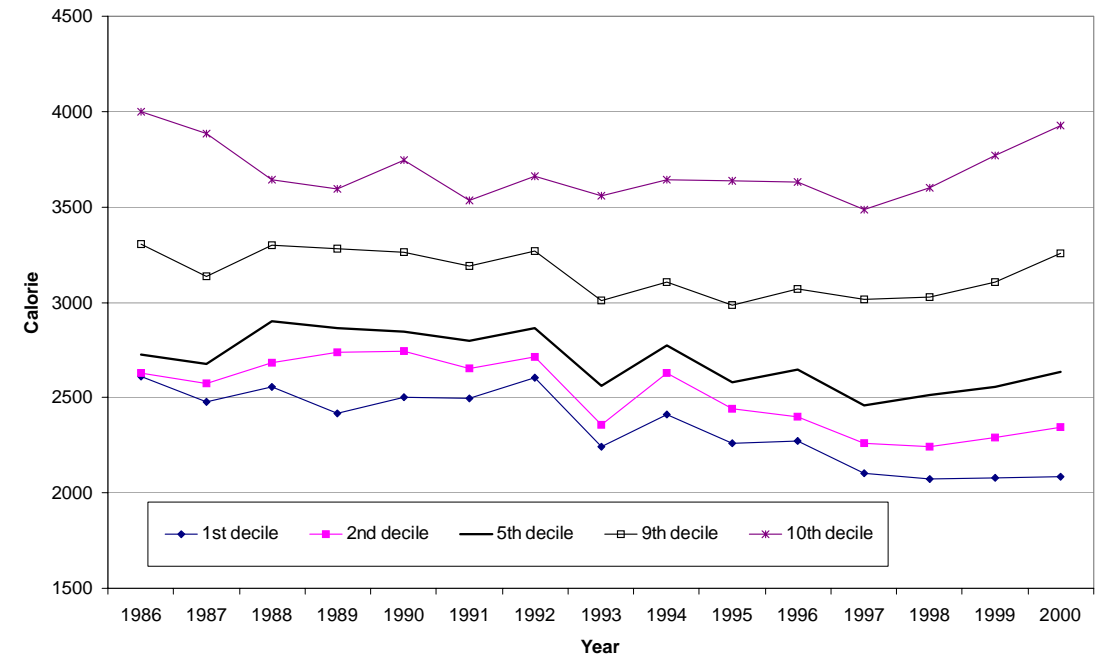


Figure 5: Calorie from different food categories for the rich and the poor: 1986-2000

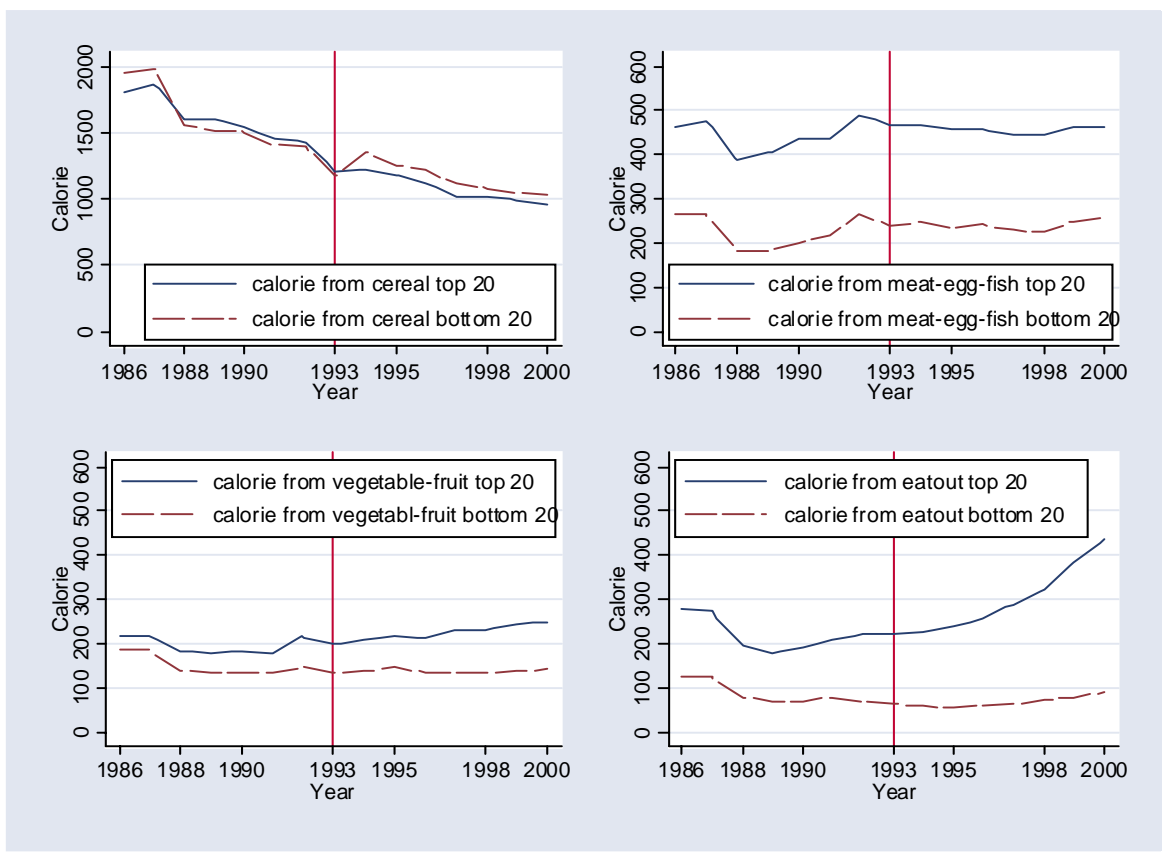

Figure 6: Expenditure elasticities: 1986-2000

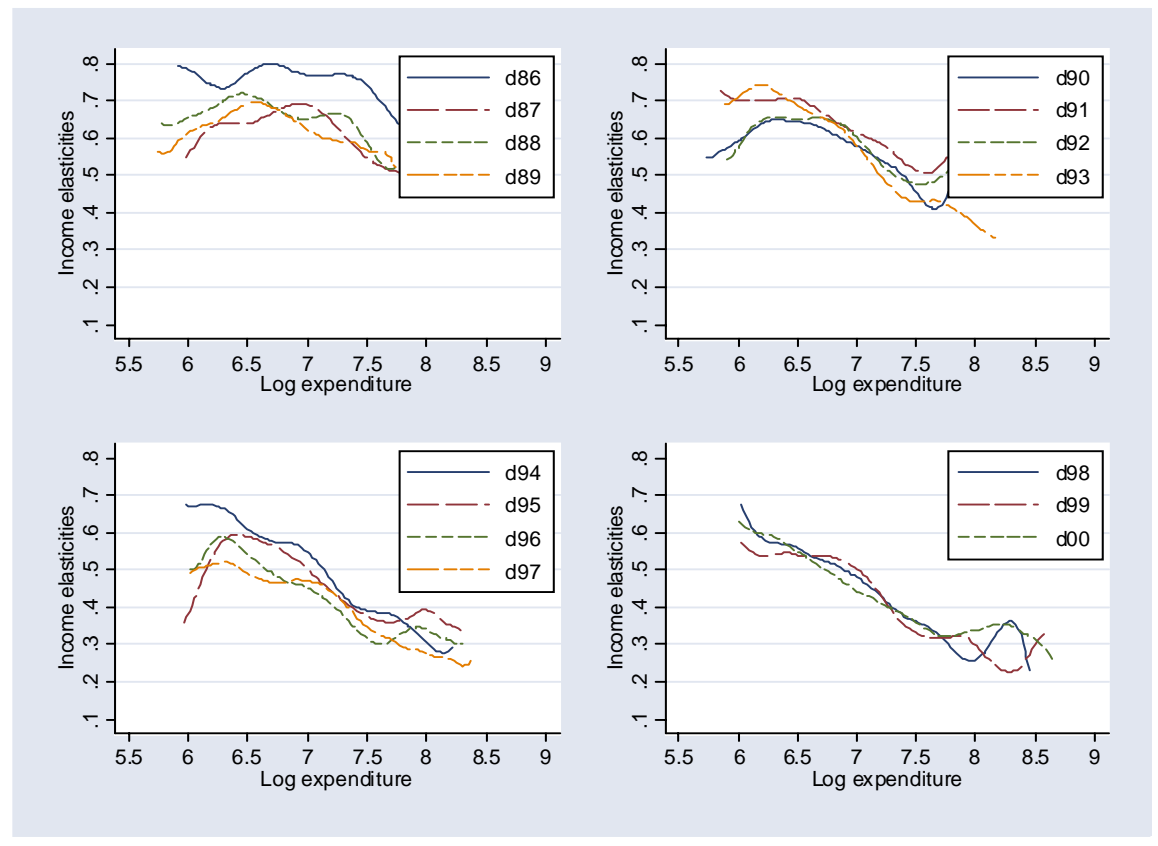


Figure 7: Income elasticities: 1986-2000
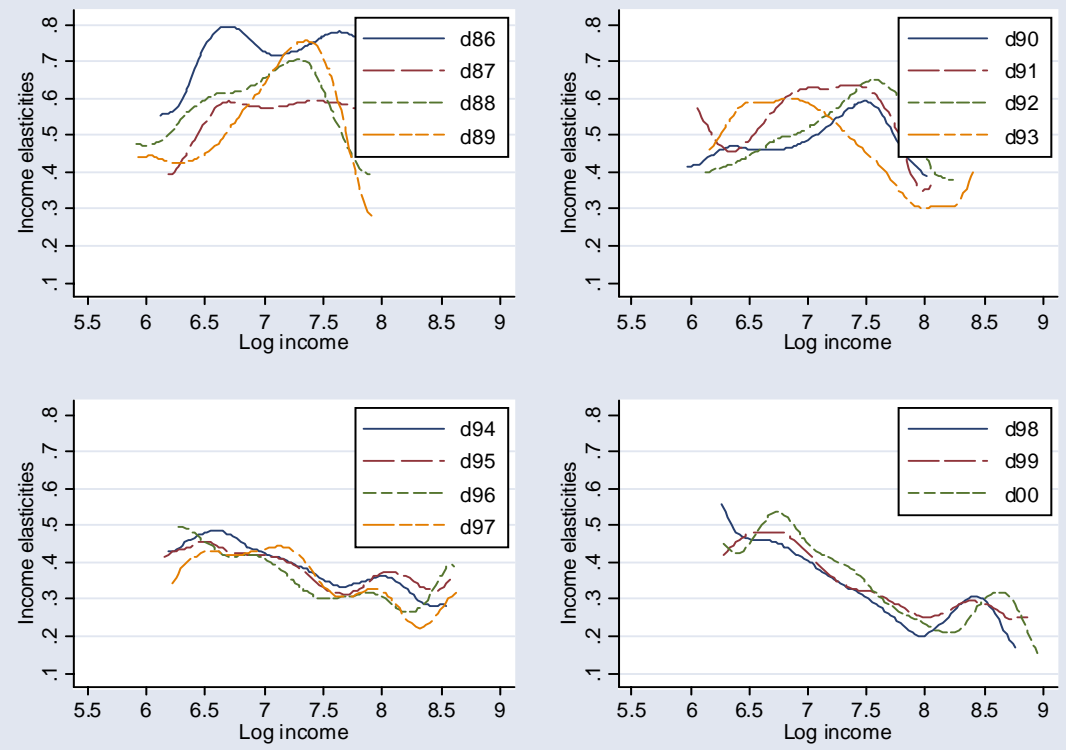

Figure 8: Sensitivity of equivalence scale adjustment: calorie and expenditure

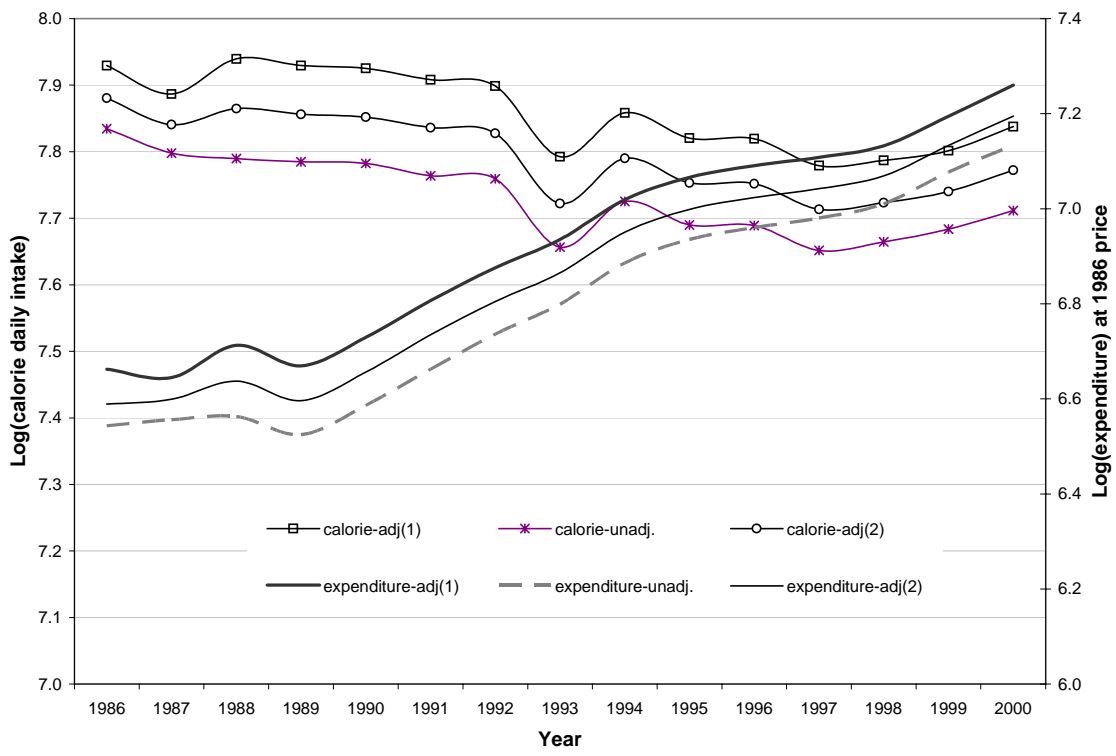


Figure 9: Expenditure elasticities (adjustment 2): 1986-2000
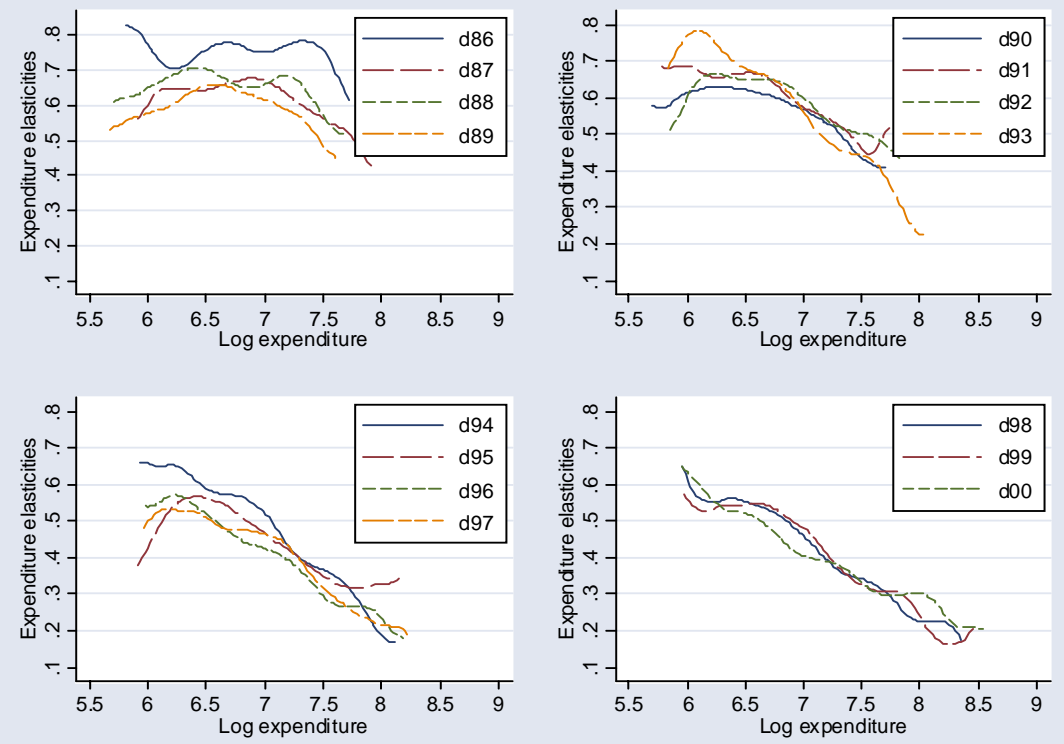

Figure 10: Expenditure elasticities (unadjusted): 1986-2000
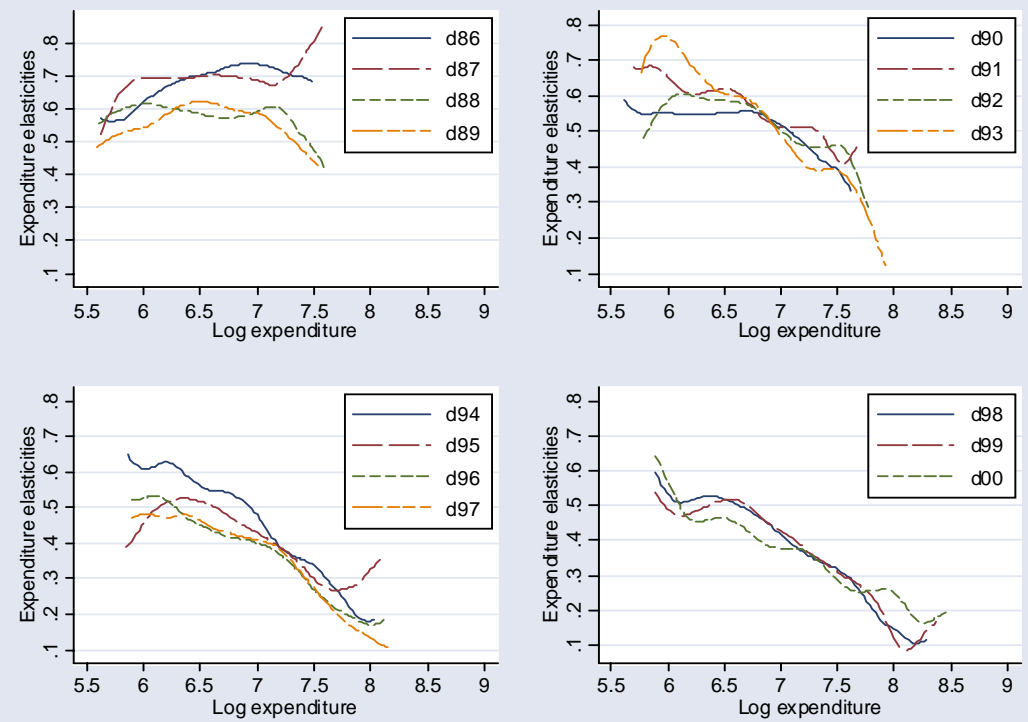
Table 1 Income and expenditure elasticities of calorie consumption at selected percentiles

\begin{tabular}{|c|c|c|c|c|c|c|c|c|c|c|}
\hline \multirow[b]{2}{*}{$\begin{array}{l}\text { Expenditure } \\
1986\end{array}$} & \multicolumn{2}{|c|}{ 10th } & \multicolumn{2}{|c|}{ 25th } & \multicolumn{2}{|c|}{ 50th } & \multicolumn{2}{|c|}{ 75th } & \multicolumn{2}{|c|}{ 90th } \\
\hline & $\begin{array}{c}\text { Elasticity } \\
0.762\end{array}$ & $\begin{array}{c}\text { St. Err. } \\
0.023\end{array}$ & $\begin{array}{c}\text { Elasticity } \\
0.798\end{array}$ & $\begin{array}{c}\text { St. Err. } \\
0.021\end{array}$ & $\begin{array}{c}\text { Elasticity } \\
0.774\end{array}$ & $\begin{array}{c}\text { St. Err. } \\
0.022\end{array}$ & $\begin{array}{c}\text { Elasticity } \\
0.765\end{array}$ & $\begin{array}{c}\text { St. Err. } \\
0.024\end{array}$ & $\begin{array}{c}\text { Elasticity } \\
0.766\end{array}$ & $\begin{array}{c}\text { St. Err. } \\
0.031\end{array}$ \\
\hline 1987 & 0.638 & 0.025 & 0.668 & 0.022 & 0.692 & 0.023 & 0.653 & 0.024 & 0.573 & 0.032 \\
\hline 1988 & 0.687 & 0.027 & 0.718 & 0.021 & 0.682 & 0.022 & 0.649 & 0.025 & 0.665 & 0.032 \\
\hline 1989 & 0.638 & 0.030 & 0.680 & 0.023 & 0.688 & 0.021 & 0.642 & 0.025 & 0.599 & 0.035 \\
\hline 1990 & 0.639 & 0.027 & 0.646 & 0.022 & 0.622 & 0.023 & 0.581 & 0.028 & 0.532 & 0.036 \\
\hline 1991 & 0.702 & 0.029 & 0.698 & 0.023 & 0.647 & 0.022 & 0.605 & 0.026 & 0.562 & 0.035 \\
\hline 1992 & 0.654 & 0.030 & 0.651 & 0.026 & 0.636 & 0.024 & 0.556 & 0.028 & 0.488 & 0.038 \\
\hline 1993 & 0.713 & 0.036 & 0.663 & 0.025 & 0.604 & 0.026 & 0.489 & 0.031 & 0.428 & 0.045 \\
\hline 1994 & 0.630 & 0.024 & 0.577 & 0.023 & 0.543 & 0.024 & 0.424 & 0.030 & 0.384 & 0.044 \\
\hline 1995 & 0.590 & 0.025 & 0.556 & 0.022 & 0.482 & 0.024 & 0.402 & 0.029 & 0.359 & 0.043 \\
\hline 1996 & 0.538 & 0.026 & 0.475 & 0.022 & 0.436 & 0.023 & 0.349 & 0.029 & 0.306 & 0.042 \\
\hline 1997 & 0.490 & 0.034 & 0.468 & 0.027 & 0.463 & 0.026 & 0.372 & 0.034 & 0.308 & 0.048 \\
\hline 1998 & 0.557 & 0.037 & 0.513 & 0.026 & 0.451 & 0.027 & 0.368 & 0.032 & 0.303 & 0.049 \\
\hline 1999 & 0.536 & 0.029 & 0.528 & 0.026 & 0.438 & 0.028 & 0.328 & 0.036 & 0.323 & 0.052 \\
\hline 2000 & 0.537 & 0.035 & 0.464 & 0.030 & 0.404 & 0.032 & 0.336 & 0.041 & 0.336 & 0.058 \\
\hline Income & Elasticity & St. Err. & Elasticity & St. Err. & Elasticity & St. Err. & Elasticity & St. Err. & Elasticity & St. Err. \\
\hline 1986 & 0.794 & 0.027 & 0.736 & 0.025 & 0.719 & 0.025 & 0.748 & 0.028 & 0.779 & 0.034 \\
\hline 1987 & 0.590 & 0.024 & 0.574 & 0.022 & 0.582 & 0.023 & 0.592 & 0.025 & 0.585 & 0.033 \\
\hline 1988 & 0.585 & 0.019 & 0.615 & 0.018 & 0.641 & 0.020 & 0.693 & 0.024 & 0.683 & 0.032 \\
\hline 1989 & 0.435 & 0.016 & 0.504 & 0.016 & 0.606 & 0.018 & 0.712 & 0.022 & 0.751 & 0.029 \\
\hline 1990 & 0.462 & 0.017 & 0.461 & 0.018 & 0.485 & 0.020 & 0.543 & 0.023 & 0.591 & 0.031 \\
\hline 1991 & 0.508 & 0.019 & 0.597 & 0.019 & 0.626 & 0.020 & 0.631 & 0.023 & 0.621 & 0.030 \\
\hline 1992 & 0.469 & 0.019 & 0.500 & 0.018 & 0.547 & 0.019 & 0.613 & 0.023 & 0.640 & 0.032 \\
\hline 1993 & 0.585 & 0.019 & 0.597 & 0.019 & 0.545 & 0.020 & 0.454 & 0.026 & 0.347 & 0.038 \\
\hline 1994 & 0.482 & 0.017 & 0.429 & 0.018 & 0.393 & 0.020 & 0.339 & 0.027 & 0.356 & 0.040 \\
\hline 1995 & 0.429 & 0.021 & 0.419 & 0.021 & 0.384 & 0.023 & 0.316 & 0.029 & 0.359 & 0.043 \\
\hline 1996 & 0.416 & 0.018 & 0.406 & 0.018 & 0.327 & 0.021 & 0.306 & 0.027 & 0.311 & 0.041 \\
\hline 1997 & 0.418 & 0.019 & 0.439 & 0.019 & 0.395 & 0.021 & 0.305 & 0.029 & 0.317 & 0.043 \\
\hline 1998 & 0.448 & 0.020 & 0.385 & 0.020 & 0.321 & 0.023 & 0.247 & 0.030 & 0.218 & 0.047 \\
\hline 1999 & 0.473 & 0.021 & 0.376 & 0.022 & 0.322 & 0.025 & 0.272 & 0.032 & 0.266 & 0.050 \\
\hline 2000 & 0.517 & 0.022 & 0.410 & 0.023 & 0.322 & 0.026 & 0.246 & 0.035 & 0.215 & 0.055 \\
\hline
\end{tabular}


Table 2 Log expenditure and income at selected percentiles

\begin{tabular}{|c|c|c|c|c|c|c|c|c|c|c|}
\hline & \multicolumn{5}{|c|}{ Expenditure } & \multicolumn{5}{|c|}{ Income } \\
\hline & 10th & 25th & 50th & 75th & 90th & 10th & 25 th & 50th & 75th & 90th \\
\hline 1986 & 6.449 & 6.692 & 6.924 & 7.145 & 7.356 & 6.696 & 6.951 & 7.186 & 7.400 & 7.599 \\
\hline 1987 & 6.475 & 6.708 & 6.944 & 7.173 & 7.406 & 6.725 & 6.977 & 7.208 & 7.435 & 7.642 \\
\hline 1988 & 6.231 & 6.472 & 6.719 & 6.956 & 7.193 & 6.440 & 6.698 & 6.941 & 7.177 & 7.399 \\
\hline 1989 & 6.182 & 6.422 & 6.664 & 6.909 & 7.160 & 6.416 & 6.673 & 6.922 & 7.159 & 7.397 \\
\hline 1990 & 6.209 & 6.466 & 6.729 & 6.979 & 7.245 & 6.479 & 6.744 & 6.995 & 7.238 & 7.478 \\
\hline 1991 & 6.317 & 6.554 & 6.805 & 7.053 & 7.301 & 6.560 & 6.803 & 7.044 & 7.277 & 7.519 \\
\hline 1992 & 6.373 & 6.615 & 6.871 & 7.127 & 7.383 & 6.631 & 6.873 & 7.127 & 7.382 & 7.643 \\
\hline 1993 & 6.364 & 6.641 & 6.935 & 7.223 & 7.513 & 6.639 & 6.902 & 7.191 & 7.484 & 7.783 \\
\hline 1994 & 6.428 & 6.711 & 7.012 & 7.323 & 7.617 & 6.661 & 6.955 & 7.273 & 7.592 & 7.914 \\
\hline 1995 & 6.485 & 6.763 & 7.064 & 7.362 & 7.659 & 6.709 & 7.000 & 7.299 & 7.618 & 7.925 \\
\hline 1996 & 6.512 & 6.781 & 7.080 & 7.384 & 7.687 & 6.742 & 7.022 & 7.329 & 7.653 & 7.974 \\
\hline 1997 & 6.505 & 6.788 & 7.101 & 7.417 & 7.724 & 6.743 & 7.036 & 7.363 & 7.697 & 8.021 \\
\hline 1998 & 6.507 & 6.807 & 7.129 & 7.445 & 7.762 & 6.769 & 7.075 & 7.408 & 7.745 & 8.068 \\
\hline 1999 & 6.550 & 6.855 & 7.185 & 7.518 & 7.848 & 6.834 & 7.149 & 7.492 & 7.836 & 8.175 \\
\hline 2000 & 6.564 & 6.901 & 7.252 & 7.612 & 7.954 & 6.835 & 7.193 & 7.558 & 7.923 & 8.276 \\
\hline
\end{tabular}

Table 3 Price elasticities for the poor and rich

\begin{tabular}{|c|c|c|c|c|c|c|c|}
\hline & & $1^{\text {st }}$ income $\mathrm{d}$ & cile & $2^{\text {nd }}$ incol & e decile & $10^{\text {th }}$ inco & ne decile \\
\hline & $\begin{array}{l}\text { Food price } \\
\text { change } \\
(\%)\end{array}$ & $\begin{array}{l}\text { Price } \\
\text { elasticity }\end{array}$ & $\begin{array}{l}\text { Reduction } \\
\text { in calorie } \\
(\%)\end{array}$ & $\begin{array}{l}\text { Price } \\
\text { elasticity }\end{array}$ & $\begin{array}{c}\text { Reduction } \\
\text { in calorie } \\
(\%)\end{array}$ & $\begin{array}{l}\text { Price } \\
\text { elasticity }\end{array}$ & $\begin{array}{c}\text { Reduction } \\
\text { in calorie } \\
(\%)\end{array}$ \\
\hline 1987 & 14.94 & -0.62 & -9.28 & -0.60 & 5.52 & -0.52 & -2.88 \\
\hline 1988 & 22.14 & -0.71 & -15.79 & -0.66 & 10.47 & -0.50 & -5.22 \\
\hline 1989 & 15.62 & -0.68 & -10.54 & -0.65 & 6.84 & -0.49 & -3.36 \\
\hline 1990 & 6.50 & -0.71 & -4.59 & -0.67 & 3.07 & -0.54 & -1.66 \\
\hline 1991 & 11.16 & -0.84 & -9.39 & -0.79 & 7.45 & -0.63 & -4.67 \\
\hline 1992 & 10.84 & -1.02 & -11.05 & -0.99 & 10.88 & -0.82 & -8.92 \\
\hline 1993 & 28.25 & -1.07 & -30.34 & -1.00 & 30.43 & -0.77 & -23.55 \\
\hline 1994 & 29.06 & -0.90 & -26.12 & -0.83 & 21.66 & -0.59 & -12.82 \\
\hline 1995 & 27.14 & -0.86 & -23.39 & -0.82 & 19.09 & -0.67 & -12.73 \\
\hline 1996 & 5.67 & -0.89 & -5.06 & -0.77 & 3.90 & -0.66 & -2.59 \\
\hline 1997 & 3.19 & -0.95 & -3.03 & -0.87 & 2.64 & -0.68 & -1.78 \\
\hline 1998 & -3.48 & -0.84 & 2.91 & -0.67 & -1.95 & -0.43 & 0.83 \\
\hline 1999 & -2.14 & -0.86 & 1.85 & -0.75 & -1.39 & -0.47 & 0.65 \\
\hline 2000 & -2.80 & -0.82 & 2.31 & -0.71 & -1.64 & -0.55 & 0.90 \\
\hline
\end{tabular}


Table 4: Sensitivity test of different equivalence scale adjustments

\begin{tabular}{|c|c|c|c|c|c|c|}
\hline & \multicolumn{3}{|c|}{$\begin{array}{l}\frac{\text { Expenditure Elasticities at } 50^{\text {th }}}{\text { per centile from equation with }} \\
\text { expenditure measure }\end{array}$} & \multicolumn{3}{|c|}{$\begin{array}{l}\text { Coefficient on Saving Rate from } \\
\text { equation with income measure }\end{array}$} \\
\hline & unadj. & $\operatorname{adj} .2$ & adj. 1 & unadj. & $\operatorname{adj} .2$ & adj. 1 \\
\hline 1986 & $0.706^{* * *}$ & $0.757^{* * *}$ & $0.774^{* * *}$ & $-0.348^{* * *}$ & $-0.389^{* * *}$ & $-0.389^{* * *}$ \\
\hline 1987 & $0.701^{* * *}$ & $0.676^{* * *}$ & $0.692^{* * *}$ & $-0.319^{* * *}$ & $-0.340^{* * *}$ & $-0.360^{* * *}$ \\
\hline 1988 & $0.578^{* * *}$ & $0.678^{* * *}$ & $0.682^{* * *}$ & $-0.341^{* * *}$ & $-0.380^{* * *}$ & $-0.367^{* * *}$ \\
\hline 1989 & $0.620^{* * *}$ & $0.658^{* * *}$ & $0.688^{* * *}$ & $-0.434^{* * *}$ & $-0.500^{* * *}$ & $-0.516^{* * *}$ \\
\hline 1990 & $0.554^{* * *}$ & $0.610^{* * *}$ & $0.622^{* * *}$ & $-0.395^{* * *}$ & $-0.443^{* * *}$ & $-0.449^{* * *}$ \\
\hline 1991 & $0.597^{* * *}$ & $0.641^{* * *}$ & $0.647^{* * *}$ & $-0.471^{* * *}$ & $-0.572^{* * *}$ & $-0.566^{* * *}$ \\
\hline 1992 & $0.570^{* * *}$ & $0.643^{* * *}$ & $0.636^{* * *}$ & $-0.457^{* * *}$ & $-0.549^{* * *}$ & $-0.554^{* * *}$ \\
\hline 1993 & $0.567^{* * *}$ & $0.616^{* * *}$ & $0.604^{* * *}$ & $-0.478^{* * *}$ & $-0.556^{* * *}$ & $-0.550^{* * *}$ \\
\hline 1994 & $0.517^{* * *}$ & $0.537^{* * *}$ & $0.543^{* * *}$ & $-0.429^{* * *}$ & $-0.509^{* * *}$ & $-0.514^{* * *}$ \\
\hline 1995 & $0.440^{* * *}$ & $0.465^{* * *}$ & $0.482^{* * *}$ & $-0.453^{* * *}$ & $-0.562^{* * *}$ & $-0.569^{* * *}$ \\
\hline 1996 & $0.405^{* * *}$ & $0.422^{* * *}$ & $0.436^{* * *}$ & $-0.426^{* * *}$ & $-0.535^{* * *}$ & $-0.535^{* * *}$ \\
\hline 1997 & $0.410^{* * *}$ & $0.461^{* * *}$ & $0.463^{* * *}$ & $-0.412^{* * *}$ & $-0.510^{* * *}$ & $-0.511^{* * *}$ \\
\hline 1998 & $0.411^{* * *}$ & $0.435^{* * *}$ & $0.451^{* * *}$ & $-0.238^{* * *}$ & $-0.332^{* * *}$ & $-0.329^{* * *}$ \\
\hline 1999 & $0.412^{* * *}$ & $0.440^{* * *}$ & $0.438^{* * *}$ & $-0.312^{* * *}$ & $-0.429^{* * *}$ & $-0.414^{* * *}$ \\
\hline 2000 & $0.375^{* * *}$ & $0.390^{* * *}$ & $0.404^{* * *}$ & $-0.288^{* * *}$ & $-0.359^{* * *}$ & $-0.369^{* * *}$ \\
\hline
\end{tabular}




\section{Appendix A. Wald tests}

Table A. Wald test results for equal parameters over he years

\begin{tabular}{lll}
\hline \hline$H_{0}$ & $\chi^{2}(59)$ & At 5\% level \\
$\theta_{86}=\theta_{87}$ & 289.6 & Rejected \\
$\theta_{87}=\theta_{88}$ & 467.8 & Rejected \\
$\theta_{88}=\theta_{89}$ & 170.6 & Rejected \\
$\theta_{89}=\theta_{90}$ & 111.6 & Rejected \\
$\theta_{90}=\theta_{91}$ & 205.9 & Rejected \\
$\theta_{91}=\theta_{92}$ & 294.5 & Rejected \\
$\theta_{92}=\theta_{93}$ & 203.3 & Rejected \\
$\theta_{93}=\theta_{94}$ & 396.2 & Rejected \\
$\theta_{94}=\theta_{95}$ & 413.2 & Rejected \\
$\theta_{95}=\theta_{96}$ & 88.0 & Rejected \\
$\theta_{96}=\theta_{97}$ & 277.9 & Rejected \\
$\theta_{97}=\theta_{98}$ & 133.3 & Rejected \\
$\theta_{98}=\theta_{99}$ & 84.6 & Rejected \\
$\theta_{99}=\theta_{00}$ & 138.3 & Rejected \\
$\theta_{00}=\theta_{86}$ & 1572.2 & Rejected \\
\hline$\chi_{0.95}^{2}(59)=77.9$ & & \\
\hline \hline
\end{tabular}


Appendix B. OLS estimates of the linear model

Table B1. OLS estimation calorie demand function (Equation 1, expenditure measure)

\begin{tabular}{|c|c|c|c|c|c|c|c|c|c|c|c|c|c|c|c|}
\hline lpcl & 1986 & 1987 & 1988 & 1989 & 1990 & 1991 & 1992 & 1993 & 1994 & 1995 & 1996 & 1997 & 1998 & 1999 & 2000 \\
\hline cons & $1.446^{* * *}$ & $2.180^{* * *}$ & $1.999^{* * *}$ & $2.378^{* * *}$ & $2.419^{* * *}$ & $2.036^{* * *}$ & $2.108^{* * *}$ & $2.355^{* * *}$ & $3.462^{* * *}$ & $3.747^{* * *}$ & $4.039^{* * *}$ & $3.971^{* * *}$ & $4.095^{* * *}$ & $4.343^{* * *}$ & $4.040^{* * *}$ \\
\hline lpexp & $0.776^{* * *}$ & $0.641^{* * *}$ & $0.656^{* * *}$ & $0.627^{* * *}$ & $0.583^{* * *}$ & $0.616^{* * *}$ & $0.575^{* * *}$ & $0.534^{* * *}$ & $0.468^{* * *}$ & $0.438^{* * *}$ & $0.401^{* * *}$ & $0.407^{* * *}$ & $0.416^{* * *}$ & $0.397^{* * *}$ & $0.385^{* * *}$ \\
\hline irstate & $-0.027^{* * *}$ & $-0.030^{* * *}$ & $-0.057^{* * *}$ & $-0.069^{* * *}$ & $-0.080^{* * *}$ & $-0.081^{* * *}$ & $-0.100^{* * *}$ & $-0.105^{* * *}$ & $-0.102^{* * *}$ & $-0.100^{* * *}$ & $-0.094^{* * *}$ & $-0.098^{* * *}$ & $-0.108^{* * *}$ & $-0.101^{* * *}$ & $-0.098^{* * *}$ \\
\hline rsave & $0.328^{* * *}$ & $0.220^{* * *}$ & $0.246^{* * *}$ & $0.168^{* * *}$ & $0.127^{* * *}$ & $0.136^{* * *}$ & $0.080^{* * *}$ & $0.055^{* * *}$ & $-0.039^{* *}$ & $-0.081^{* * *}$ & $-0.097^{* * *}$ & $-0.069^{* * *}$ & -0.009 & -0.007 & 0.008 \\
\hline lprice1 & $-0.540^{* * *}$ & $-0.630^{* * *}$ & $-0.696^{* * *}$ & $-0.644^{* * *}$ & $-0.697^{* * *}$ & $-0.827^{* * *}$ & $-0.988^{* * *}$ & $-1.018^{* * *}$ & $-0.815^{* * *}$ & $-0.818^{* * *}$ & $-0.806^{* * *}$ & $-0.832^{* * *}$ & $-0.695^{* * *}$ & $-0.697^{* * *}$ & $-0.682^{* * *}$ \\
\hline lprice2 & $-0.491^{* * *}$ & $-0.600^{* * *}$ & $-0.648^{* * *}$ & $-0.620^{* * *}$ & $-0.666^{* * *}$ & $-0.800^{* * *}$ & $-0.958^{* * *}$ & $-0.980^{* * *}$ & $-0.810^{* * *}$ & $-0.799^{* * *}$ & $-0.764^{* * *}$ & $-0.800^{* * *}$ & $-0.614^{* * *}$ & $-0.673^{* * *}$ & $-0.651^{* * *}$ \\
\hline lprice3 & $-0.475^{* * *}$ & $-0.587^{* * *}$ & $-0.632^{* * *}$ & $-0.595^{* * *}$ & $-0.644^{* * *}$ & $-0.784^{* * *}$ & $-0.941^{* * *}$ & $-0.949^{* * *}$ & $-0.785^{* * *}$ & $-0.750^{* * *}$ & $-0.715^{* * *}$ & $-0.739^{* * *}$ & $-0.609^{* * *}$ & $-0.626^{* * *}$ & $-0.635^{* * *}$ \\
\hline lprice4 & $-0.461^{* * *}$ & $-0.576^{* * *}$ & $-0.620^{* * *}$ & $-0.579^{* * *}$ & $-0.633^{* * *}$ & $-0.766^{* * *}$ & $-0.928^{* * *}$ & $-0.922^{* * *}$ & $-0.756^{* * *}$ & $-0.722^{* * *}$ & $-0.697^{* * *}$ & $-0.707^{* * *}$ & $-0.604^{* * *}$ & $-0.538^{* * *}$ & $-0.593^{* * *}$ \\
\hline lprice 5 & $-0.448^{* * *}$ & $-0.570^{* * *}$ & $-0.606^{* * *}$ & $-0.566^{* * *}$ & $-0.631^{* * *}$ & $-0.751^{* * *}$ & $-0.917^{* * *}$ & $-0.921^{* * *}$ & $-0.745^{* * *}$ & $-0.733^{* * *}$ & $-0.706^{* * *}$ & $-0.681^{* * *}$ & $-0.528^{* * *}$ & $-0.565^{* * *}$ & $-0.589^{* * *}$ \\
\hline lprice6 & $-0.444^{* * *}$ & $-0.558^{* * *}$ & $-0.589^{* * *}$ & $-0.560^{* * *}$ & $-0.610^{* * *}$ & $-0.737^{* * *}$ & $-0.903^{* * *}$ & $-0.889^{* * *}$ & $-0.742^{* * *}$ & $-0.713^{* * *}$ & $-0.682^{* * *}$ & $-0.635^{* * *}$ & $-0.460^{* * *}$ & $-0.515^{* * *}$ & $-0.558^{* * *}$ \\
\hline lprice 7 & $-0.435^{* * *}$ & $-0.554^{* * *}$ & $-0.568^{* * *}$ & $-0.541^{* * *}$ & $-0.596^{* * *}$ & $-0.729^{* * *}$ & $-0.901^{* * *}$ & $-0.874^{* * *}$ & $-0.691^{* * *}$ & $-0.680^{* * *}$ & $-0.651^{* * *}$ & $-0.597^{* * *}$ & $-0.473^{* * *}$ & $-0.490^{* * *}$ & $-0.557^{* * *}$ \\
\hline lprice8 & $-0.421^{* * *}$ & $-0.559^{* * *}$ & $-0.558^{* * *}$ & $-0.527^{* * *}$ & $-0.583^{* * *}$ & $-0.714^{* * *}$ & $-0.872^{* * *}$ & $-0.851^{* * *}$ & $-0.644^{* * *}$ & $-0.604^{* * *}$ & $-0.633^{* * *}$ & $-0.590^{* * *}$ & $-0.428^{* * *}$ & $-0.476^{* * *}$ & $-0.483^{* * *}$ \\
\hline lprice9 & $-0.406^{* * *}$ & $-0.538^{* * *}$ & $-0.544^{* * *}$ & $-0.513^{* * *}$ & $-0.586^{* * *}$ & $-0.702^{* * *}$ & $-0.871^{* * *}$ & $-0.806^{* * *}$ & $-0.636^{* * *}$ & $-0.614^{* * *}$ & $-0.601^{* * *}$ & $-0.528^{* * *}$ & $-0.415^{* * *}$ & $-0.413^{* * *}$ & $-0.475^{* * *}$ \\
\hline lprice 10 & $-0.375^{* * *}$ & $-0.523^{* * *}$ & $-0.488^{* * *}$ & $-0.467^{* * *}$ & $-0.539^{* * *}$ & $-0.636^{* * *}$ & $-0.790^{* * *}$ & $-0.757^{* * *}$ & $-0.583^{* * *}$ & $-0.703^{* * *}$ & $-0.729^{* * *}$ & $-0.706^{* * *}$ & $-0.551^{* * *}$ & $-0.515^{* * *}$ & $-0.542^{* * *}$ \\
\hline lctinc & 0.011 & $0.123^{* * *}$ & $0.194^{* * *}$ & $0.086^{* * *}$ & $0.148^{* * *}$ & $0.226^{* * *}$ & $0.317^{* * *}$ & $0.316^{* * *}$ & $0.166^{* * *}$ & $0.194^{* * *}$ & $0.190^{* * *}$ & $0.195^{* * *}$ & $0.131^{* * *}$ & $0.162^{* * *}$ & $0.232^{* * *}$ \\
\hline hhage & $0.574^{* * *}$ & $0.533^{* * *}$ & $1.522^{* * *}$ & $1.527^{* * *}$ & $2.115^{* * *}$ & $1.894^{* * *}$ & $2.098^{* * *}$ & $2.459^{* * *}$ & $1.881^{* * *}$ & $1.990^{* * *}$ & $1.885^{* * *}$ & $1.854^{* * *}$ & $1.571^{* * *}$ & $0.864^{* * *}$ & $1.580^{* * *}$ \\
\hline shhage & -0.011 & 0.019 & $-0.996^{* * *}$ & $-0.953^{* * *}$ & $-1.417^{* * *}$ & $-1.158^{* * *}$ & $-1.258^{* * *}$ & $-1.586^{* * *}$ & $-1.041^{* * *}$ & $-1.199^{* * *}$ & $-1.029^{* * *}$ & $-1.065^{* * *}$ & $-0.773^{* * *}$ & -0.046 & $-0.816^{* * *}$ \\
\hline hed 2 & $0.044^{* * *}$ & $0.024^{* * *}$ & $0.035^{* * *}$ & $0.029^{* * *}$ & $0.042^{* * *}$ & $0.042^{* * *}$ & $0.045^{* * *}$ & $0.051^{* * *}$ & $0.032^{* * *}$ & $0.028^{* * *}$ & $0.040^{* * *}$ & $0.037^{* * *}$ & $0.024^{* * *}$ & $0.022^{* * *}$ & $0.051^{* * *}$ \\
\hline hed3 & $0.053^{* * *}$ & $0.025^{* * *}$ & $0.041^{* * *}$ & $0.033^{* * *}$ & $0.032^{* * *}$ & $0.029^{* * *}$ & $0.037^{* * *}$ & $0.039^{* * *}$ & $0.037^{* * *}$ & $0.042^{* * *}$ & $0.048^{* * *}$ & $0.059^{* * *}$ & $0.049^{* * *}$ & $0.048^{* * *}$ & $0.064^{* * *}$ \\
\hline hed4 & $0.083^{* * *}$ & $0.065^{* * *}$ & $0.077^{* * *}$ & $0.074^{* * *}$ & $0.078^{* * *}$ & $0.078^{* * *}$ & $0.079^{* * *}$ & $0.075^{* * *}$ & $0.073^{* * *}$ & $0.074^{* * *}$ & $0.083^{* * *}$ & $0.094^{* * *}$ & $0.089^{* * *}$ & $0.083^{* * *}$ & $0.104^{* * *}$ \\
\hline hed5 & $0.121^{* * *}$ & $0.106^{* * *}$ & $0.104^{* * *}$ & $0.105^{* * *}$ & $0.108^{* * *}$ & $0.110^{* * *}$ & $0.116^{* * *}$ & $0.125^{* * *}$ & $0.106^{* * *}$ & $0.095^{* * *}$ & $0.093^{* * *}$ & $0.116^{* * *}$ & $0.112^{* * *}$ & $0.112^{* * *}$ & $0.118^{* * *}$ \\
\hline $\mathrm{rk}$ & -0.004 & $-0.021^{* * *}$ & $-0.020^{* * *}$ & $-0.020^{* * *}$ & $-0.029^{* * *}$ & $-0.034^{* * *}$ & $-0.042^{* * *}$ & $-0.054^{* * *}$ & $-0.064^{* * *}$ & $-0.066^{* * *}$ & $-0.064^{* * *}$ & $-0.064^{* * *}$ & $-0.069^{* * *}$ & $-0.079^{* * *}$ & $-0.072^{* * *}$ \\
\hline sratio & 0.006 & $0.058^{* *}$ & $0.039^{* *}$ & $0.046^{* *}$ & $0.060^{* * *}$ & 0.026 & $0.077^{* * *}$ & $0.073^{* * *}$ & $0.072^{* * *}$ & $0.083^{* * *}$ & $0.093^{* * *}$ & $0.087^{* * *}$ & $0.101^{* * *}$ & $0.082^{* * *}$ & $0.046^{* *}$ \\
\hline radultf & $0.176^{* * *}$ & $0.142^{* * *}$ & $0.071^{* *}$ & 0.035 & 0.051 & $0.137^{* * *}$ & $0.059^{*}$ & $0.101^{* * *}$ & 0.049 & 0.029 & $0.054^{*}$ & $0.084^{* *}$ & 0.040 & $0.092^{* * *}$ & $0.119^{* * *}$ \\
\hline rteenf & 0.046 & $0.077^{* *}$ & $-0.173^{* * *}$ & $-0.148^{* * *}$ & $-0.080^{* * *}$ & $-0.088^{* * *}$ & $-0.124^{* * *}$ & $-0.219^{* * *}$ & $-0.259^{* * *}$ & $-0.257^{* * *}$ & $-0.284^{* * *}$ & $-0.264^{* * *}$ & $-0.293^{* * *}$ & $-0.240^{* * *}$ & $-0.225^{* * *}$ \\
\hline rteenm & $0.157^{* * *}$ & $0.148^{* * *}$ & -0.026 & -0.016 & 0.000 & 0.005 & -0.018 & $-0.084^{* *}$ & $-0.188^{* * *}$ & $-0.174^{* * *}$ & $-0.209^{* * *}$ & $-0.179^{* * *}$ & $-0.172^{* * *}$ & $-0.148^{* * *}$ & $-0.115^{* * *}$ \\
\hline reldm & $0.371^{* * *}$ & $0.362^{* * *}$ & $0.392^{* * *}$ & $0.318^{* * *}$ & $0.353^{* * *}$ & $0.423^{* * *}$ & $0.314^{* * *}$ & $0.440^{* * *}$ & $0.369^{* * *}$ & $0.334^{* * *}$ & $0.422^{* * *}$ & $0.466^{* * *}$ & $0.407^{* * *}$ & $0.443^{* * *}$ & $0.504^{* * *}$ \\
\hline reldf & $0.264^{* * *}$ & $0.201^{* * *}$ & $0.298^{* * *}$ & $0.300^{* * *}$ & $0.314^{* * *}$ & $0.308^{* * *}$ & $0.375^{* * *}$ & $0.355^{* * *}$ & $0.342^{* * *}$ & $0.363^{* * *}$ & $0.316^{* * *}$ & $0.374^{* * *}$ & $0.343^{* * *}$ & $0.353^{* * *}$ & $0.374^{* * *}$ \\
\hline rkid05 & $0.156^{* * *}$ & $0.202^{* * *}$ & $-0.056^{*}$ & $-0.070^{* *}$ & -0.046 & 0.055 & -0.006 & 0.003 & -0.012 & 0.002 & 0.018 & $0.075^{*}$ & $0.127^{* * *}$ & 0.044 & $0.136^{* * *}$ \\
\hline rkid610 & $0.270^{* * *}$ & $0.307^{* * *}$ & $0.054^{* *}$ & 0.026 & $0.094^{* * *}$ & $0.117^{* * *}$ & $0.087^{* * *}$ & $0.060^{*}$ & 0.026 & 0.027 & 0.041 & 0.046 & $0.099^{* * *}$ & $0.105^{* * *}$ & $0.145^{* * *}$ \\
\hline rkid115 & $0.355^{* * *}$ & $0.348^{* * *}$ & $0.198^{* * *}$ & $0.170^{* * *}$ & $0.204^{* * *}$ & $0.207^{* * *}$ & $0.150^{* * *}$ & $0.134^{* * *}$ & $0.112^{* * *}$ & $0.061^{* *}$ & 0.042 & $0.072^{* *}$ & $0.097^{* * *}$ & $0.079^{* * *}$ & $0.184^{* * *}$ \\
\hline No obs & 12175 & 13155 & 13674 & 12953 & 13618 & 13686 & 16816 & 16614 & 16722 & 16843 & 16790 & 16765 & 16782 & 16811 & 16797 \\
\hline $\mathrm{R}^{2}$ & 0.5095 & 0.4646 & 0.4622 & 0.4683 & 0.4781 & 0.4702 & 0.5677 & 0.5259 & 0.5421 & 0.5113 & 0.4956 & 0.4784 & 0.4698 & 0.4756 & 0.4886 \\
\hline
\end{tabular}


Table B2: OLS estimation calorie demand function (Equation 1, income measure)

\begin{tabular}{|c|c|c|c|c|c|c|c|c|c|c|c|c|c|c|c|}
\hline & 1986 & 1987 & 1988 & 1989 & 1990 & 1991 & 1992 & 1993 & 1994 & 1995 & 1996 & 1997 & 1998 & 1999 & 2000 \\
\hline Const. & $1.926^{* * *}$ & $2.765^{* * *}$ & $2.729^{* * *}$ & $3.031^{* * *}$ & $3.089^{* * *}$ & $2.552^{* * *}$ & $2.646^{* * *}$ & $3.057^{* * *}$ & $4.143^{* * *}$ & $4.156^{* * *}$ & $4.449^{* * *}$ & $4.360^{* * *}$ & $4.895^{* * *}$ & $4.978^{* * *}$ & $4.560^{* * *}$ \\
\hline lpinc & $0.715^{* * *}$ & $0.559^{* * *}$ & $0.559^{* * *}$ & $0.540^{* * *}$ & $0.489^{* * *}$ & $0.540^{* * *}$ & $0.492^{* * *}$ & $0.431^{* * *}$ & $0.366^{* * *}$ & $0.376^{* * *}$ & $0.337^{* * *}$ & $0.348^{* * *}$ & $0.295^{* * *}$ & $0.304^{* * *}$ & $0.304^{* * *}$ \\
\hline irstate & $-0.023^{* * *}$ & $-0.030^{* * *}$ & $-0.056^{* * *}$ & $-0.068^{* * *}$ & $-0.078^{* * *}$ & $-0.079^{* * *}$ & $-0.097^{* * *}$ & $-0.104^{* * *}$ & $-0.096^{* * *}$ & $-0.095^{* * *}$ & $-0.088^{* * *}$ & $-0.094^{* * *}$ & $-0.103^{* * *}$ & $-0.093^{* * *}$ & $-0.089^{* * *}$ \\
\hline rsave & $-0.399^{* * *}$ & $-0.365^{* * *}$ & $-0.381^{* * *}$ & $-0.510^{* * *}$ & $-0.455^{* * *}$ & $-0.561^{* * *}$ & $-0.559^{* * *}$ & $-0.552^{* * *}$ & $-0.518^{* * *}$ & $-0.566^{* * *}$ & $-0.538^{* * *}$ & $-0.523^{* * *}$ & $-0.320^{* * *}$ & $-0.417^{* * *}$ & $-0.369^{* * *}$ \\
\hline lprice1 & $-0.489^{* * *}$ & $-0.598^{* * *}$ & $-0.631^{* * *}$ & $-0.582^{* * *}$ & $-0.641^{* * *}$ & $-0.791^{* * *}$ & $-0.956^{* * *}$ & $-0.969^{* * *}$ & $-0.756^{* * *}$ & $-0.770^{* * *}$ & $-0.750^{* * *}$ & $-0.766^{* * *}$ & $-0.543^{* * *}$ & $-0.576^{* * *}$ & $-0.570^{* * *}$ \\
\hline lprice2 & $-0.441^{* * *}$ & $-0.574^{* * *}$ & $-0.596^{* * *}$ & $-0.574^{* * *}$ & $-0.626^{* * *}$ & $-0.777^{* * *}$ & $-0.941^{* * *}$ & $-0.954^{* * *}$ & $-0.774^{* * *}$ & $-0.775^{* * *}$ & $-0.729^{* * *}$ & $-0.771^{* * *}$ & $-0.517^{* * *}$ & $-0.602^{* * *}$ & $-0.585^{* * *}$ \\
\hline lprice3 & $-0.426^{* * *}$ & $-0.563^{* * *}$ & $-0.584^{* * *}$ & $-0.552^{* * *}$ & $-0.607^{* * *}$ & $-0.766^{* * *}$ & $-0.928^{* * *}$ & $-0.934^{* * *}$ & $-0.764^{* * *}$ & $-0.735^{* * *}$ & $-0.693^{* * *}$ & $-0.724^{* * *}$ & $-0.537^{* * *}$ & $-0.580^{* * *}$ & $-0.589^{* * *}$ \\
\hline lprice4 & $-0.411^{* * *}$ & $-0.554^{* * *}$ & $-0.576^{* * *}$ & $-0.540^{* * *}$ & $-0.601^{* * *}$ & $-0.753^{* * *}$ & $-0.919^{* * *}$ & $-0.918^{* * *}$ & $-0.745^{* * *}$ & $-0.719^{* * *}$ & $-0.686^{* * *}$ & $-0.704^{* * *}$ & $-0.548^{* * *}$ & $-0.505^{* * *}$ & $-0.564^{* * *}$ \\
\hline 1price 5 & $-0.398^{* * *}$ & $-0.548^{* * *}$ & $-0.565^{* * *}$ & $-0.531^{* * *}$ & $-0.601^{* * *}$ & $-0.743^{* * *}$ & $-0.912^{* * *}$ & $-0.928^{* * *}$ & $-0.742^{* * *}$ & $-0.736^{* * *}$ & $-0.704^{* * *}$ & $-0.683^{* * *}$ & $-0.487^{* * *}$ & $-0.550^{* * *}$ & $-0.572^{* * *}$ \\
\hline lprice6 & $-0.394^{* * *}$ & $-0.538^{* * *}$ & $-0.549^{* * *}$ & $-0.526^{* * *}$ & $-0.584^{* * *}$ & $-0.729^{* * *}$ & $-0.902^{* * *}$ & $-0.900^{* * *}$ & $-0.751^{* * *}$ & $-0.722^{* * *}$ & $-0.687^{* * *}$ & $-0.647^{* * *}$ & $-0.443^{* * *}$ & $-0.511^{* * *}$ & $-0.548^{* * *}$ \\
\hline lprice7 & $-0.386^{* * *}$ & $-0.534^{* * *}$ & $-0.531^{* * *}$ & $-0.509^{* * *}$ & $-0.571^{* * *}$ & $-0.723^{* * *}$ & $-0.903^{* * *}$ & $-0.895^{* * *}$ & $-0.708^{* * *}$ & $-0.699^{* * *}$ & $-0.663^{* * *}$ & $-0.619^{* * *}$ & $-0.472^{* * *}$ & $-0.504^{* * *}$ & $-0.564^{* * *}$ \\
\hline lprice8 & $-0.367^{* * *}$ & $-0.540^{* * *}$ & $-0.522^{* * *}$ & $-0.498^{* * *}$ & $-0.561^{* * *}$ & $-0.714^{* * *}$ & $-0.879^{* * *}$ & $-0.884^{* * *}$ & $-0.667^{* * *}$ & $-0.630^{* * *}$ & $-0.654^{* * *}$ & $-0.610^{* * *}$ & $-0.427^{* * *}$ & $-0.500^{* * *}$ & $-0.490^{* * *}$ \\
\hline lprice9 & $-0.350^{* * *}$ & $-0.519^{* * *}$ & $-0.512^{* * *}$ & $-0.488^{* * *}$ & $-0.566^{* * *}$ & $-0.705^{* * *}$ & $-0.883^{* * *}$ & $-0.852^{* * *}$ & $-0.679^{* * *}$ & $-0.643^{* * *}$ & $-0.618^{* * *}$ & $-0.536^{* * *}$ & $-0.409^{* * *}$ & $-0.423^{* * *}$ & $-0.487^{* * *}$ \\
\hline lprice 10 & $-0.318^{* * *}$ & $-0.503^{* * *}$ & $-0.457^{* * *}$ & $-0.447^{* * *}$ & $-0.529^{* * *}$ & $-0.647^{* * *}$ & $-0.804^{* * *}$ & $-0.814^{* * *}$ & $-0.626^{* * *}$ & $-0.708^{* * *}$ & $-0.714^{* * *}$ & $-0.686^{* * *}$ & $-0.506^{* * *}$ & $-0.494^{* * *}$ & $-0.541^{* * *}$ \\
\hline lctinc & 0.036 & $0.164^{* * *}$ & $0.207^{* * *}$ & $0.099^{* * *}$ & $0.173^{* * *}$ & $0.253^{* * *}$ & $0.349^{* * *}$ & $0.364^{* * *}$ & $0.213^{* * *}$ & $0.230^{* * *}$ & $0.225^{* * *}$ & $0.223^{* * *}$ & $0.186^{* * *}$ & $0.207^{* * *}$ & $0.272^{* * *}$ \\
\hline hhage & $0.617^{* * *}$ & $0.528^{* *}$ & $1.530^{* * *}$ & $1.540^{* * *}$ & $2.141^{* * *}$ & $1.926^{* * *}$ & $2.213^{* * *}$ & $2.360^{* * *}$ & $1.880^{* * *}$ & $1.984^{* * *}$ & $1.887^{* * *}$ & $1.852^{* * *}$ & $1.565^{* * *}$ & $0.804^{* * *}$ & $1.631^{* * *}$ \\
\hline shhage & -0.020 & 0.038 & $-0.982^{* * *}$ & $-0.954^{* * *}$ & $-1.423^{* * *}$ & $-1.182^{* * *}$ & $-1.374^{* * *}$ & $-1.482^{* * *}$ & $-1.048^{* * *}$ & $-1.194^{* * *}$ & $-1.029^{* * *}$ & $-1.061^{* * *}$ & $-0.779^{* * *}$ & 0.018 & $-0.878^{* * *}$ \\
\hline hed 2 & $0.046^{* * *}$ & $0.023^{* *}$ & $0.034^{* * *}$ & $0.027^{* * *}$ & $0.041^{* * *}$ & $0.041^{* * *}$ & $0.045^{* * *}$ & $0.051^{* * *}$ & $0.031^{* * *}$ & $0.026^{* * *}$ & $0.037^{* * *}$ & $0.035^{* * *}$ & $0.017^{*}$ & $0.018^{* *}$ & $0.049^{* * *}$ \\
\hline hed 3 & $0.055^{* * *}$ & $0.024^{* * *}$ & $0.042^{* * *}$ & $0.032^{* * *}$ & $0.032^{* * *}$ & $0.029^{* * *}$ & $0.037^{* * *}$ & $0.037^{* * *}$ & $0.035^{* * *}$ & $0.040^{* * *}$ & $0.046^{* * *}$ & $0.057^{* * *}$ & $0.043^{* * *}$ & $0.043^{* * *}$ & $0.061^{* * *}$ \\
\hline hed4 & $0.083^{* * *}$ & $0.064^{* * *}$ & $0.076^{* * *}$ & $0.074^{* * *}$ & $0.076^{* * *}$ & $0.076^{* * *}$ & $0.077^{* * *}$ & $0.072^{* * *}$ & $0.068^{* * *}$ & $0.071^{* * *}$ & $0.079^{* * *}$ & $0.089^{* * *}$ & $0.080^{* * *}$ & $0.075^{* * *}$ & $0.096^{* * *}$ \\
\hline hed5 & $0.118^{* * *}$ & $0.102^{* * *}$ & $0.100^{* * *}$ & $0.099^{* * *}$ & $0.103^{* * *}$ & $0.103^{* * *}$ & $0.109^{* * *}$ & $0.118^{* * *}$ & $0.098^{* * *}$ & $0.088^{* * *}$ & $0.084^{* * *}$ & $0.109^{* * *}$ & $0.095^{* * *}$ & $0.097^{* * *}$ & $0.108^{* * *}$ \\
\hline $\mathrm{rk}$ & $-0.007^{* * *}$ & $-0.023^{* * *}$ & $-0.025^{* * *}$ & $-0.026^{* * *}$ & $-0.036^{* * *}$ & $-0.040^{* * *}$ & $-0.047^{* * *}$ & $-0.058^{* * *}$ & $-0.072^{* * *}$ & $-0.072^{* * *}$ & $-0.070^{* * *}$ & $-0.071^{* * *}$ & $-0.083^{* * *}$ & $-0.090^{* * *}$ & $-0.081^{* * *}$ \\
\hline sratio & 0.010 & $0.063^{* * *}$ & $0.038^{* *}$ & $0.046^{* *}$ & $0.059^{* * *}$ & 0.023 & $0.075^{* * *}$ & $0.074^{* * *}$ & $0.070^{* * *}$ & $0.082^{* * *}$ & $0.098^{* * *}$ & $0.084^{* * *}$ & $0.089^{* * *}$ & $0.082^{* * *}$ & $0.041^{*}$ \\
\hline radultf & $0.177^{* * *}$ & $0.143^{* * *}$ & $0.063^{* *}$ & 0.028 & 0.036 & $0.133^{* * *}$ & 0.049 & $0.103^{* * *}$ & 0.045 & 0.022 & 0.052 & $0.084^{* *}$ & 0.044 & $0.092^{* * *}$ & $0.117^{* * *}$ \\
\hline rteenf & 0.020 & 0.051 & $-0.197^{* * *}$ & $-0.162^{* * *}$ & $-0.092^{* * *}$ & $-0.095^{* * *}$ & $-0.142^{* * *}$ & $-0.224^{* * *}$ & $-0.273^{* * *}$ & $-0.271^{* * *}$ & $-0.296^{* * *}$ & $-0.276^{* * *}$ & $-0.297^{* * *}$ & $-0.250^{* * *}$ & $-0.229^{* * *}$ \\
\hline rteenm & $0.124^{* * *}$ & $0.108^{* * *}$ & -0.050 & -0.036 & -0.021 & -0.005 & -0.034 & $-0.091^{* *}$ & $-0.204^{* * *}$ & $-0.188^{* * *}$ & $-0.226^{* * *}$ & $-0.192^{* * *}$ & $-0.166^{* * *}$ & $-0.155^{* * *}$ & $-0.120^{* * *}$ \\
\hline reldm & $0.398^{* * *}$ & $0.389^{* * *}$ & $0.413^{* * *}$ & $0.339^{* * *}$ & $0.382^{* * *}$ & $0.439^{* * *}$ & $0.355^{* * *}$ & $0.471^{* * *}$ & $0.398^{* * *}$ & $0.356^{* * *}$ & $0.454^{* * *}$ & $0.497^{* * *}$ & $0.474^{* * *}$ & $0.492^{* * *}$ & $0.547^{* * *}$ \\
\hline reldf & $0.274^{* * *}$ & $0.213^{* * *}$ & $0.315^{* * *}$ & $0.311^{* * *}$ & $0.332^{* * *}$ & $0.324^{* * *}$ & $0.385^{* * *}$ & $0.377^{* * *}$ & $0.377^{* * *}$ & $0.382^{* * *}$ & $0.337^{* * *}$ & $0.396^{* * *}$ & $0.387^{* * *}$ & $0.387^{* * *}$ & $0.409^{* * *}$ \\
\hline rkid05 & $0.164^{* * *}$ & $0.208^{* * *}$ & $-0.060^{*}$ & $-0.063^{*}$ & -0.029 & 0.060 & 0.006 & 0.012 & -0.008 & 0.002 & 0.021 & $0.079^{*}$ & $0.149^{* * *}$ & 0.056 & $0.154^{* * *}$ \\
\hline rkid610 & $0.269^{* * *}$ & $0.298^{* * *}$ & $0.054^{* *}$ & 0.026 & $0.116^{* * *}$ & $0.128^{* * *}$ & $0.098^{* * *}$ & $0.075^{* *}$ & 0.035 & 0.034 & 0.049 & 0.049 & $0.127^{* * *}$ & $0.121^{* * *}$ & $0.166^{* * *}$ \\
\hline rkid115 & $0.347^{* * *}$ & $0.336^{* * *}$ & $0.198^{* * *}$ & $0.171^{* * *}$ & $0.222^{* * *}$ & $0.214^{* * *}$ & $0.158^{* * *}$ & $0.152^{* * *}$ & $0.127^{* * *}$ & $0.066^{* *}$ & 0.048 & $0.082^{* * *}$ & $0.133^{* * *}$ & $0.098^{* * *}$ & $0.203^{* * *}$ \\
\hline No. obs & 12176 & 13155 & 13674 & 12953 & 13618 & 13686 & 16816 & 16614 & 16722 & 16843 & 16790 & 16765 & 16782 & 16811 & 16797 \\
\hline $\mathrm{R}^{2}$ & 0.46 & 0.42 & 0.42 & 0.44 & 0.44 & 0.45 & 0.55 & 0.51 & 0.52 & 0.49 & 0.48 & 0.46 & 0.42 & 0.44 & 0.46 \\
\hline
\end{tabular}


Appendix C. Estimation results of the partial linear model

Table C1. Parameter estimates of the partial linear model of calorie demand (equation 2, expenditure measure)

\begin{tabular}{|c|c|c|c|c|c|c|c|c|c|c|c|c|c|c|c|}
\hline ddlpcl & 86 & 87 & 88 & 989 & 990 & 1991 & 1992 & 1993 & 1994 & 1995 & 1996 & 1997 & 1998 & 1999 & 2000 \\
\hline ddirstate & & $.026^{* * *}$ & $.065^{* * *}$ & $.064^{* * *}$ & $.077^{* * *}$ & $-0.080^{* * *}$ & $-0.095^{* * *}$ & $-0.102^{* * *}$ & $-0.107^{* * *}$ & $-0.111^{* * *}$ & $-0.100^{* * *}$ & $-0.097^{* * *}$ & $-0.113^{* * *}$ & $-0.107^{* * *}$ & $-0.098^{* * *}$ \\
\hline ddrsave & & & & & & & & & 0.006 & & & & -0.011 & 0.014 & 0.014 \\
\hline ddlprice1 & & **** & $.713^{* * *}$ & $-0.675^{* * *}$ & $.706^{* * *}$ & (**** & $1010^{* * *}$ & $-1.074^{* * *}$ & $0.899^{* * *}$ & $-0.862^{* * *}$ & $-0.892^{* * *}$ & $-0.949^{* * *}$ & $-0.836^{* * *}$ & & $-0.824^{* * *}$ \\
\hline ddlpri & & & & & & & & & & & & & & & \\
\hline ddlprice3 & & & & & & & & & & & & & & & $-0.672^{* * *}$ \\
\hline ddlprice4 & & & & & & & & & & & & & & & \\
\hline ice5 & & & & & & & & & & & & & & & \\
\hline & & & $-0.596^{* * *}$ & $-0.584^{* * *}$ & $-0.598^{* * *}$ & $-0.720^{* * *}$ & $-0.902^{* * *}$ & $-0.876^{* * *}$ & & & $-0.653^{* * *}$ & $-0.644^{* * *}$ & & & $-0.516^{* * *}$ \\
\hline $\mathrm{ddl}_{1}$ & & & & -0.55 & -0.59 & -0.70 & & & $-0.664^{* * *}$ & & & & -0.4 & & $2^{* * *}$ \\
\hline & & & & & & & & & & & & & & & \\
\hline & & & & & -0.56 & -0.68 & $-0.87^{\prime}$ & & $0.617^{* * *}$ & & & & & & \\
\hline & & & & & & & & & & & & & & & \\
\hline & 0 & & & & & & & & & & & & & & \\
\hline & & & & 1 & & & *** & & $* * *$ & & & *** & & & \\
\hline & $-c$ & & & -0.9 & & & & & & & & & & & \\
\hline & & 012 & 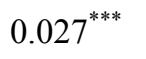 & 0.038 & 0.047 & $* * *$ & 0.04 & 0.05 & 0.03 & & & 0.03 & & & \\
\hline & & & & & & & & & & & & & & & \\
\hline & & & & $* *$ & 0 & $.080^{* * *}$ & *** & *** & & & & & & & \\
\hline & & & & & & & & & & & & & & & \\
\hline ddrk & & & $010^{* * * *}$ & $-0.018^{* * *}$ & $-0.029^{* * *}$ & $-0.039^{* * *}$ & & $3^{* * *}$ & $-0.060^{* * *}$ & & & -0.06 & & & $-0.074^{* * *}$ \\
\hline & -( & & & & & 0.015 & & & & & & & & & \\
\hline & & 0 & $0.101^{* * *}$ & 0.035 & $0.054^{*}$ & $0.150^{* * *}$ & 0.046 & $0.081^{* *}$ & $0.067^{* *}$ & $0.054^{*}$ & $0.071^{* *}$ & $0.076^{* *}$ & $0.062^{*}$ & & $0.100^{* * *}$ \\
\hline & 035 & & & $-0.134^{* * *}$ & $-0.066^{* *}$ & $-0.085^{* *}$ & $-0.112^{* * *}$ & $-0.180^{* * *}$ & $-0.266^{* * *}$ & $-0.258^{* * *}$ & $-0.269^{* * *}$ & $-0.269^{* * *}$ & $-0.266^{* * *}$ & $-0.272^{* * *}$ & $-0.243^{* * *}$ \\
\hline ddrt & $7 \tau^{* * *}$ & $0.130^{* * *}$ & -0.015 & -0.033 & 0.021 & 0.025 & -0.008 & $-0.093^{* *}$ & $-0.143^{* * *}$ & $-0.126^{* * *}$ & $-0.210^{* * *}$ & $-0.190^{* * *}$ & -0.1 & -0.1 & $-0.144^{* * *}$ \\
\hline & & $272^{* * *}$ & $423^{* * *}$ & $0.360^{* * *}$ & $0.371^{* * *}$ & $0.469^{* * *}$ & $0.325^{* * *}$ & $0.447^{* * *}$ & $0.409^{* * *}$ & $0.375^{* * *}$ & $0.459^{* * *}$ & $0.434^{* * *}$ & $0.444^{* * *}$ & $0.515^{* * *}$ & $0.481^{* * *}$ \\
\hline & & & $0.365^{* * *}$ & & & & $0.333^{* * *}$ & $0.363^{* * *}$ & $0.358^{* * *}$ & $0.366^{* * *}$ & $0.352^{* * *}$ & $0.434^{* * *}$ & 0.38 & $0.368^{* * *}$ & $0.361^{* * *}$ \\
\hline & $7^{* * *}$ & $223^{* * *}$ & -0.046 & $-0.086^{* *}$ & $-0.072^{* *}$ & $0.083^{* *}$ & -0.035 & 0.000 & 0.011 & 0.001 & 0.020 & 0.064 & $0.126^{* * *}$ & 0.015 & $0.077^{* *}$ \\
\hline & & & & 0.018 & & & $0.056^{*}$ & $0.056^{*}$ & & & 0.023 & $0.059^{*}$ & $0.090^{* * *}$ & $0.089^{* * *}$ & $0.127^{* * *}$ \\
\hline & $57 * *$ & *** & $0.221^{* * *}$ & $0.148^{* * *}$ & $0^{* * *}$ & $0.211^{* * *}$ & $0.128^{* * *}$ & & $0.110^{* * *}$ & $0.053^{*}$ & & & & & $0.161^{* * *}$ \\
\hline & & & & 052 & 3617 & 3685 & 16815 & 16613 & 16721 & 16842 & 6789 & 16764 & 16781 & 16810 & 16796 \\
\hline $\mathrm{R}^{2}$. & 0.3284 & 0.3469 & 0.3338 & 0.3476 & 0.3692 & 0.3728 & 0.5002 & 0.4236 & 0.473 & 0.4157 & 0.4048 & 0.3692 & 0.3398 & 0.3508 & 0.3536 \\
\hline
\end{tabular}


Table C2: Parameter estimates of the partial linear model of calorie demand (equation 2, income measure)

\begin{tabular}{|c|c|c|c|c|c|c|c|c|c|c|c|c|c|c|c|}
\hline & 86 & 1987 & 988 & 989 & 1990 & 1991 & 1992 & 1993 & 1994 & 1995 & 1996 & 1997 & 1998 & 1999 & \\
\hline ddirstate & & $-0.038^{* * *}$ & $.056^{* * *}$ & $.068^{* * *}$ & $-0.080^{* * *}$ & $-0.086^{* * *}$ & $-0.095^{* * *}$ & $-0.118^{* * *}$ & $-0.094^{* * *}$ & $-0.088^{* * *}$ & $-0.090^{* * *}$ & $-0.088^{* * *}$ & $-0.102^{* * *}$ & $-0.091^{* * *}$ & $-0.098^{* * *}$ \\
\hline ddrsave & & & **** & & & & & & & & & & & & \\
\hline ddlprice1 & & & & & & & & & & & & & & & $-0.801^{* * *}$ \\
\hline ddlprice2 & & & & & & & & & & & & & & & $-0.637^{* * *}$ \\
\hline ddlprice 3 & & & & & & & & & & & & & & & \\
\hline ddlprice4 & & $-0.550^{* * *}$ & $0.593^{* * *}$ & $-0.537^{* * *}$ & $-0.597^{* * *}$ & $-0.760^{* * *}$ & $-0.933^{* * *}$ & $-0.911^{* * *}$ & $-0.749^{* * *}$ & $-0.689^{* * *}$ & $-0.605^{* * *}$ & $-0.703^{* * *}$ & $-0.545^{* * *}$ & $-0.509^{* * *}$ & $-0.541^{* * *}$ \\
\hline ddlprice 5 & & $-c$ & $.573^{* * *}$ & $.526^{* * *}$ & -0.60 & -0.75 & -0.92 & & $.734^{* * *}$ & $-0.711^{* * *}$ & $4^{* * *}$ & -0.62 & *** & **** & $9^{* * *}$ \\
\hline ddlprice 6 & & & & & & & & & & & & & & & $-0.516^{* * *}$ \\
\hline ddlp & & $-c$ & & & & -0.71 & & & $-0.681^{* * *}$ & & & & & & \\
\hline ddlp & & & & & & $-0.697^{* * *}$ & & & & & & & & & \\
\hline ddlp & & $-0.513^{* * *}$ & & $-0.442^{* * *}$ & & $-0.683^{* * *}$ & & & & $-0.673^{* * *}$ & & & & & \\
\hline ddlp & & -0.50 & -( & & & -0.60 & & & & -0.68 & & & & & \\
\hline ddlc & ( & & & & & & & & & & & & & & \\
\hline ddhh & & $0.648^{* * *}$ & 1.66 & & & 1.915 & 2.43 & & & & & & & & $4^{* * *}$ \\
\hline ddshl & 018 & -0.132 & & & & & & & & $-1.349^{* * *}$ & & & & 0.055 & \\
\hline ddh & & $0.022^{* *}$ & 0 & $.032^{* * *}$ & 0.036 & 0.046 & & & $0.021^{* *}$ & 0.011 & & & & & $0.039^{* * *}$ \\
\hline ddhe & & $0.020^{* *}$ & & & & *** & & & & & & & & & \\
\hline ddh & & 0.063 & $* * *$ & $.074^{* * *}$ & & 0.073 & & & & & & & & & $0.087^{* * *}$ \\
\hline ddhed5 & & $0.095^{* * *}$ & $* * *$ & $.099^{* * *}$ & & $0.091^{* * *}$ & $0.107^{* * *}$ & & & $0.088^{* * *}$ & & & & & $0.100^{* * *}$ \\
\hline ddrk & $009^{* * *}$ & $-0.024^{* * *}$ & $-0.027^{* * *}$ & $-0.022^{* * *}$ & $-0.036^{* * *}$ & $-0.043^{* * *}$ & $-0.047^{* * *}$ & $-0.056^{* * *}$ & $-0.069^{* * *}$ & $-0.079^{* * *}$ & & $-0.072^{* * *}$ & & $-0.090^{* * *}$ & $-0.081^{* * *}$ \\
\hline ddsra & 06 & $0.057^{* *}$ & $0.048^{* * *}$ & $0.031^{*}$ & $0.051^{* * *}$ & $0.032^{*}$ & $0.070^{* * *}$ & $0.064^{* * *}$ & $0.070^{* * *}$ & $0.075^{* * *}$ & $0.080^{* * *}$ & $0.069^{* * *}$ & & $0.074^{* * *}$ & $0.047^{* *}$ \\
\hline ddradultf & & & & 0.024 & & & & & & & & & & & $0.125^{* * *}$ \\
\hline ddrteenf & 028 & $0.056^{*}$ & $-0.176^{* * *}$ & $-0.185^{* * *}$ & $-0.111^{* * *}$ & $-0.104^{* * *}$ & $-0.126^{* * *}$ & $-0.177^{* * *}$ & $-0.274^{* * *}$ & $-0.280^{* * *}$ & $-0.224^{* * *}$ & $-0.303^{* * *}$ & $-0.299^{* * *}$ & $-0.229^{* * *}$ & $-0.228^{* * *}$ \\
\hline ddrte & & & -0.041 & -0.025 & -0.037 & 0.005 & -0.030 & & & $-0.158^{* * *}$ & & & & & $-0.122^{* * *}$ \\
\hline ddre & **** & $* * *$ & $442^{* * *}$ & $0.369^{* * *}$ & $0.397^{* * *}$ & $0.423^{* * *}$ & $0.369^{* * *}$ & $0.520^{* * *}$ & $0.379^{* * *}$ & $0.410^{* * *}$ & $0.532^{* * *}$ & $0.516^{* * *}$ & $0.449^{* * *}$ & $0.512^{* * *}$ & $0.572^{* * *}$ \\
\hline ddreldf & & & $0.308^{* * *}$ & $0.309^{* * *}$ & $0.348^{* * *}$ & $0.312^{* * *}$ & $0.417^{* * *}$ & $0.364^{* * *}$ & $0.363^{* * *}$ & $0.381^{* * *}$ & $0.339^{* * *}$ & $0.391^{* * *}$ & $0.407^{* * *}$ & $0.377^{* * *}$ & $0.434^{* * *}$ \\
\hline ddrkid05 & $160^{* * *}$ & $0.231^{* * *}$ & -0.023 & $-0.071^{* *}$ & -0.009 & 0.051 & $0.065^{*}$ & 0.029 & -0.036 & -0.011 & $0.091^{* *}$ & $0.071^{*}$ & $0.119^{* * *}$ & 0.056 & $.162^{* * *}$ \\
\hline ddrkid610 & $1^{* * *}$ & $202^{* * * *}$ & $0.063^{* *}$ & 0.034 & $0.108^{* * *}$ & $0.141^{* * *}$ & $0.147^{* * *}$ & $0.091^{* * *}$ & 0.028 & 0.020 & $0.104^{* * *}$ & $0.057^{*}$ & $0.105^{* * *}$ & $0.139^{* * *}$ & $0.136^{* * *}$ \\
\hline & & & & & & & & & & & & & & & \\
\hline & & & & & & & & & & & & & & & 6796 \\
\hline $\mathrm{R}^{2}$ & 0.35 & 0.36 & 0.35 & 0.39 & 0.38 & 0.40 & 0.52 & 0.46 & 0.48 & 0.45 & 0.43 & 0.40 & 0.36 & 0.37 & 0.38 \\
\hline
\end{tabular}




\section{Appendix D. Yatchew test}

Following Yatchew $(1998$, p. 703) linear model is tested against the partial linear model. Yatchew's test is based upon comparing two estimates of the residual variance. First, after sorting the data by $\log (Y), s_{\text {diff }}^{2}$ is defined as $1 /(2 N) \sum\left(\Delta \ln K-\widetilde{\theta}^{\prime} \Delta Z\right)^{2}$, where $\widetilde{\theta}$ is the estimator of $\beta, \delta$, and $\gamma$ in Equation 2. Second, $\sin _{\text {lin }}{ }^{2}$ is the averaged sum of squared residuals of the parametric (linear) regression. Yatchew shows that, under the null hypothesis that the parametric specification is correct, the test statistic:

$V=N^{1 / 2}\left(s_{\text {lin }}^{2}-s_{\text {diff }}^{2}\right) / s_{\text {diff }}^{2}$

is approximately standard normal. This gives a one-sided specification test for the parametric against the partially linear model. The results of Yatchew (1998) tests for the linear against the partial linear model are presented in the following table. The linear model is clearly rejected except for seven years $(1986,1988,1991-1994$, and 1998).

\section{Table D. Yatchew Test Results}

\begin{tabular}{lll}
\hline \hline Year & Test statistics & Rejection at 5\% level \\
1986 & 0.762 & Not rejected \\
1987 & 0.899 & Not rejected \\
1988 & 2.639 & Rejected \\
1989 & 1.659 & Rejected \\
1990 & 2.553 & Rejected \\
1991 & 1.345 & Not rejected \\
1992 & 0.255 & Not rejected \\
1993 & 0.401 & Not rejected \\
1994 & -0.877 & Not rejected \\
1995 & 2.160 & Rejected \\
1996 & 3.410 & Rejected \\
1997 & 1.852 & Rejected \\
1998 & 1.121 & Not rejected \\
1999 & 1.666 & Rejected \\
2000 & 3.773 & Rejected \\
\hline \hline
\end{tabular}

